\title{
Seismological investigations in the Olduvai basin and Ngorongoro Volcanic Highlands (western flank of the North Tanzanian Divergence)
}

\author{
Laura Parisi ${ }^{1}$, Ian Stanistreet ${ }^{2,3}$, Jackson Njau $^{3,4}$, Kathy Schick ${ }^{3,5}$, \\ Nicholas $\operatorname{Toth}^{3,5}$ \& P. Martin Mai ${ }^{1}$ \\ 1 PSE Division, King Abdullah University of Science and Technology, Saudi Arabia \\ 2 Department of Earth, Ocean and Ecological Sciences, University of Liverpool, UK \\ 3 The Stone Age Institute, Bloomington, USA \\ 4 Department of Earth \& Atmospheric Sciences, Indiana University, USA \\ ${ }^{5}$ Department of Anthropology, Indiana University, USA
}

Corresponding author: Laura Parisi - laura.parisi@kaust.edu.sa

\begin{abstract}
We present data and results of a passive seismic experiment that we operated between June 2016 and May 2018 in the Ngorongoro Conservation Area (northern Tanzania), located on the western side of the eastern branch of the Eastern African Rift System. The motivation for this experiment is two-fold (i) investigating the extension of the Olduvai basin, referred to also as the "Cradle of Human Mankind", as it hosted a variety of paleoenvironments exploited by hominins during their evolution; (ii) studying the link between the fault system in the main Eastern African Rift and in its western flank. We conduct detailed data-quality analysis of the seismic recordings based upon ambient noise characterization and numerical waveform simulations. Our dataset is of good quality and we observe that local magnitude can be overestimated
\end{abstract}


up to at least, 0.23 , due to wave-amplifications effects occurring at sites with loose sedimentary material. Based on a new but simple approach using power spectral density measurements, we calculate the thickness of sedimentary basins. This allows us mapping the bottom of the Olduvai paleolake confirming that the its sedimentary record may be at least $200 \mathrm{~m}$ deeper than previously inferred from core drilling. We also map the bottom of the Olbalbal depression for the first time. In addition, we present a seismicity map of the Ngorongoro Conservation Area with unprecedented detail. The seismicity depicts the suture zone between the Tanzanian craton and the Mozambique belt, and reveals that the fault system in the western flank of the rift merges at depth into a single detachment which joins the Manyara fault on the western side of the main rift valley.

\section{INTRODUCTION}

The Ngorongoro Conservation Area (NCA) is a protected territory in northern Tanzania established in 1959 to support the coexistence of the indigenous semi-nomadic Maasai population with wildlife and tourism. Moreover, since the early 1930's the territory of the NCA has been an area of extensive archeological research on human evolution and human-environmental dynamics. In 1979, the NCA became a World Heritage Site because of its natural, cultural and archaeological uniqueness and importance.

In the past these factors have limited the installation of wide seismological networks, however, within the Olduvai gorge Coring Project (OGCP) a small-scale broadband seismic network was set up. The OGCP aimed to drill the depth of the Olduvai sedimentary basin, located within the NCA. Prior to the OGCP, the Olduvai basin was thought to have recorded approximately $2 \mathrm{Ma}$ of hominin evolutionary changes [Hay, 1976]. The coring of four boreholes and an active-seismic experiment revealed that the Olduvai basin extends much deeper, recording as much as $\sim 4 \mathrm{Ma}$ of geological and paleoenvironmental history [Lu et al. , 2019].

The extension and evolution of the Olduvai basin was effected by extensional fault system and tectonics in the area [e.g., Stollhofen \& Stanistreet, 2012] relating to the edge of the African Rift System. However, the network of synsedimentary faults is currently only known at the surface and from active seismic experiments [Lu et al. , 2019]. Moreover, the Oduvai basin and its system of extensional faults are part of the larger rift system of the North Tanzanian 
Divergence [NTD, e.g., Dawson, 1992; Le Gall et al. , 2008]. However, how the Olduvai fault system connects at depth to the main rift faults is not well understood.

In this study, we present the results of the Olduvai Passive Seismic (OPS) experiment comprising 17 broadband seismic stations installed within the NCA. The objectives of such experiment are to investigate the geometry of the Olduvai basin to support paleoecological and sedimentological investigations and to identify the active faults to understand their role within the NTD.

\section{Geological setting and paleoanthropological relevance}

The Eastern Africa Rift (EAR) is a divergent boundary separating the Nubian and Somali plates. The EAR started to develop during the Miocene and propagates southwards from the Afar Triple Junction to Mozambique [e.g., Ebinger, 2005; Calais et al. , 2006, and references therein]. The EAR splits into the Western and Eastern branches around the Archean Tanzanian craton. The North Tanzanian Divergence [NTD, Dawson, 1992] represents the southernmost tip of the eastern branch of the EAR where the Magadi-Natron rift system diverges toward south into the three arms of the Eyasi, Manyara and Pangani fault systems [Le Gall et al. , 2008] (Figure 1).

Our investigations are focussed within the NCA, and where the eastern part of the $100-\mathrm{km}$ long Eyasi fault is located, marked by a spectacular $400 \mathrm{~m}$ scarp, bounding the very shallow, high-salinity Eyasi lake. The associated syn-rift sediments are less than $2 \mathrm{~km}$ thick [Ebinger et al. , 1997]. The Eyasi fault develops mostly in the Archean Tanzanian craton and continues eastewards into the Proterozoic Mozambique belt [Foster et al. , 1997; Ebinger et al. , 1997]. The buried contact between the Tanzania craton and the Mozambique belt is not well identified (Figure 1). However, it is exposed in Kenya and just north of the Eyasi fault, [Foster et al. , 1997] and it is estimated to dip at $45^{\circ}$ eastwards [Ebinger et al. , 1997].

Volcanic activity in the NTD occurred along zones of pre-existing weakness between the Tanzanian craton and the Mozambique belt [Smith, 1994; Mana et al. , 2015] (Figure 1). The activity started around $6 \mathrm{Ma}$, showing increased intensity $\sim 2.3 \mathrm{Ma}$ [Mana et al. , 2015]. Volcanic centers show migration trends toward the east and north-east [Mana et al. , 2015]. In the NTD, the only volcano currently active is Oldoinyo Lengai, a unique carbonatitic volcano located in the northernmost part of the Ngorongoro Volcanic Highlands (NVH, Figure 1). The NVH are 
approximately aligned SW-NE for $\sim 80 \mathrm{~km}$ and include many extinct volcanoes. The volcanic centers of Mt. Oldeani ( 1.6 Ma), Mt. Satiman ( 4.6 Ma) and Mt. Lemagrut ( 2.4 Ma) are located in the southern NCA [Mollel et al. , 2011]. Further north, the most prominent volcanic centers are Mt. Olmoti (2.1 Ma c.a) [Mollel et al. , 2011] and the Ngorongoro caldera of 20 km diameter; its original volcanic edifice may have reached $6000 \mathrm{~m}$ in height [Hay, 1976]. Latest measurements from drilling of the Olduvai basin report its period of activity to have lasted from 2.18 Ma to 2.00 Ma ago [Stanistreet et al. , 2020a].

The NVH are dissected by several diversely oriented faults (Figure 2a). The Ngorongoro caldera is bounded by a NE-SW striking fault passing along its western crater rim (henceforth referred as WCR fault from now). Mt. Satiman and Mt. Oldeani are crossed by NNE-SSW striking faults that seem to join the Meshili and the WCR faults, respectively. Mt. Lemagrut is dissected by a N-S striking fault that is considered part of the Eyasi bounding fault [e.g., Le Gall et al. , 2008], despite a sharp change in strike between these two fault segments. For simplicity, we will refer to this N-S fault segment as the Lemagrut fault.

The NVH provided the volcanic material, as well as surface and underground water, that filled up the Pleistocene Olduvai sedimentary basin located in the center of the NCA [Stanistreet et al. , 2020a] (Figures 1 and 2a). Olmoti volcano is considered to be the main provider of tuffs in the Olduvai basin [McHenry et al. , 2008] between 1.85 to 1.80 Ma [Deino, 2012] while the Olduvai paleolake is interpreted as a rift-platform basin of the main rift valley [Ashley \& Hay, 2002]. At present, the Olduvai basin is incised by a 90 m-deep homonymous gorge which exposes $\sim 2$ Ma of geological record (Figures 1 and 2a) although a deeper $135 \mathrm{~m}$ of additional fill was encountered in drillcore [Stanistreet et al. , 2020a].

The extension and water level of Olduvai paleolake varied rapidly due to the fact that it occupies a closed basin and semi-arid conditions resulted in high rates of evaporation, that made it susceptible to short-term climatically forced variations in lake-level (Figure 2a). Recent borehole investigations [Stanistreet et al. , 2020a,b] revealed that the sedimentary section extends to at least $245 \mathrm{~m}$ depth, with deep layers dating back to 2.25 to $2.5 \mathrm{Ma}$ [Deino et al. , 2020]. Moreover, the recent seismic-refraction experiment carried out with the OGCP [Lu et al. , 2019] showed that the complete sedimentary sequence within the Olduvai basin reaches as deep as $\sim 425 \mathrm{~m}$ in the deepest part, suggesting that the basin potentially started to develop $\sim 4$ Ma ago [Lu et al. , 2019]. 
The paleolake started to shrink about 0.8 Ma ago [Stanistreet et al. , 2020a] when the Olbalbal depression, located just east of the paleolake, became the primary basin (Figure 2a). The Olbalbal depression currently hosts an ephemeral lake in its northern part and accumulate sediments coming from the Olduvai gorge on the west and the NVH on the east. The current topographic low of the Olbalbal depression is an indication that at least one of the faults at its edges is currently active.

Faults responsible for the development of the paleolake are synthetic to the main rift, dipping towards SE, and are named from east to west as First, Second, Third, Fourth, and Fifth [Reck, 1914; Hay, 1976] (Figure 2a). Ashley \& Hay [2002] and Stollhofen \& Stanistreet [2012] recognized that a Sixth fault, mapped but unnamed by Hay [1976], was controlling, together with the Fifth fault, the western margin of the lake [Stollhofen \& Stanistreet, 2012; Lu et al. , 2019; Stanistreet et al. , 2020a]. Among the antithetic faults, Meshili is the longest one and bounds eastern edge of the Olbalbal depression (Figure 2a). Dip angles of the Olduvai fault system are not known, although Hay [1976] portrays Second fault where it reaches the surface at an angle of $72^{\circ}$.

The role of the extensional fault system during the evolution of the basin was important for paleoecology while early hominins (i.e, Homo habilis, Homo erectus and Homo sapiens) lived around the paleolake. The basin compartments offered a mosaic of paleoenviroments that supported hominins and their evolution, during the existence of the paleolake [Stollhofen \& Stanistreet, 2012]. Also, fault scarps formed natural dams, preventing the paleolake from being filled by tuff and lava incident from the NVH [Stollhofen \& Stanistreet, 2012].

Because of the exposure of more than $90 \mathrm{~m}$ of sedimentary sequence, the Olduvai gorge is one of the first sites where archaeological and paleontological remains informed paleoanthropologists about hominin evolution extending back to 2 Ma [Leakey, 1971; Hay, 1976]. Moreover, the recent discovery that the Olduvai basin might have recorded human evolutionary contexts back to 4 Ma covering the time of the Laetoli footprints, is inspiring new geological and geophysical investigations in the entire Olduvai basin, including the Olbalbal depression. In fact, the Olduvai gorge is not the only relevant site in the NCA: Laetoli, located in proximity of the southern NVH (Figure 2a), hosts footprints of Australopithecus afarensis [e.g., Leakey \& Hay, 1979; Masao et al. , 2016] within tuffs that were erupted 3.6 Ma ago (probably from the Satiman volcano [e.g., Mollel et al. , 2011]).

For all these reasons, NCA is one of the most important locations in the world to understand 
the human evolution and, therefore, one of the main motivations of this study is to investigate the geometry of the paleolake and the Olbalbal depression to support the next sedimentological and anthropological investigations.

\section{Previous seismological investigations}

Global earthquake catalogues report a few events with magnitudes larger than 3 in the NCA since 1970, rendering this region as seismically quiet compared to the main rift valley (Figure 1). A large number of events with magnitudes smaller than 3 were recorded by a temporary network operating in 2013-2014 [Weinstein et al. , 2017]. This network targeted the main rift valley and did not have the the resolution needed to image the fault system of the Olduvai basin at depth and the southern NVH. A six-month long passive seismology experiment also covered the area between the Eyasi and Manyara rift branches [Albaric et al. , 2010], but the duration of the experiment did not allow to map the relatively quiet faults of the NHV and Olduvai basin. Thus, the aim of our experiment is to complement the previous seismic networks by densely covering the Olduvai basin and the southern NVH to specifically investigate the tectonics of the western rift flank.

In the following, we present the OPS seismic network together with an evaluation of its performance and a validation of the collected dataset. In addition, we show an approach to use continuous broadband seismic data for rapid estimation of the thickness of the sedimentary basins. Finally, we present the a high-resolution seismicity map of the NCA.

\section{THE OPS NETWORK}

During the OPS experiment (June 2016 to May 2018) a total of 17 sites were occupied (Figure 2a), but not all stations recorded during the entire duration of the experiment. Most installations were completed during the campaigns in May 2016 and May 2017, the last station was installed in September 2017. The OPS sites were visited every four months to collect the seismic data and for technical maintenance. An overview of the data availability for each each station is shown in Figure 2b. The network covered an area of $\sim 3000 \mathrm{~km}^{2}$, with a station spacing between 8 and $15 \mathrm{~km}$. 


\section{Site selection and station installation}

The landscape of the NCA is dotted with small villages of the Maasai, a local tribe that still practices traditional livestock grazing. Only a few public buildings (e.g. schools, local administration) and tourist accommodation exist. Humans share the territory with wild animals which includes, among others, wildebeest, zebra, gazelles, buffalo and elephants. At the time of our experiments, only one main access road existed but numerous tracks allowed $4 \mathrm{x} 4$ vehicles to drive within the reserved area. In general, the NCA can be considered a wild and remote area. These factors needed to be taken into account in the choices for seismic installation sites which sometimes were not optimal. In the trade-off between safety (from wildlife, theft, deliberate destruction) and quiescence (distance from human noise sources), we installed 13 stations within Maasai villages, one in the backyard of a school, one in proximity of a museum, and two in proximity of administration buildings.

The KAUST pool of broadband seismic stations consists of Nanometrics Trillium Compact Posthole $120 \mathrm{~s}$ sensors designed for direct burial, i.e., the sensor is placed directly into the ground and insulated only by fine sand filling the space between sensor and the wall of the hole. These sensors can tolerate up to $2.5^{\circ}$ of tilt. At most OPS sites, fairly cohesive soil being rich in gravel and boulders was encountered. Therefore, direct burial of sensors was difficult, ensuring a stable position and levelling $\left(\right.$ tilt $\left.<2.5^{\circ}\right)$. Instead, we used a concrete tile $(\sim 5 \mathrm{~cm}$ thick and $\sim 20$ $\mathrm{cm}$ in diameter) to create a leveled surface. For protection and insulation, we placed a plastic bucket over the sensor, adding polyurethane foam to increase thermal insulation and reduce air circulation between sensor and bucket. Burial depths ranged between $60-120 \mathrm{~cm}$. In most cases, the maximum burial depth was constrained by layers of impenetrable volcanic material. Sensors were connected to Nanometrics Centaur digitizers (operating in continuous mode with a sampling rate of $200 \mathrm{~Hz}$ ) that were placed within Nanometrics carrying cases. To prevent water flooding of the carrying box and drowning the electrical equipment during heavy rain, small drill holes were placed at the bottom of the box to allow water drainage. Each seismic installation was powered by a lead-acid battery charged by a $12 \mathrm{~W}$ solar panel.

Despite the small aperture of the OPS network, we encountered varying weather conditions and altitudes ranging from 1400 to $2300 \mathrm{~m}$ over even short distances within the NCA. Thus, severe rains during the two wet seasons (March-May and November- December) and high levels of 
dust during the peak of the dry season (August-September) occasionally prevented the sunlight from reaching the solar panels, leading to power shortages and thus creating data gaps at some stations (Figure $2 \mathrm{~b}$ ).

\section{VALIDATION OF THE OPS DATASET}

The identification of potential pitfalls in the data is essential before using the dataset in seismological investigations. Therefore, before processing of the dataset for the seismicity study, we calculate synthetic seismograms for a regional earthquake to compare them in terms of waveform timing and amplitudes to our data recorded by the OPS seismic network.

We simulate waveforms for the regional Mw 5.1 earthquake (22 October 2017), that occurred close to Tanganyika lake (Figure $3 \mathrm{a}$ ) at $27 \mathrm{~km}$ depth at an average epicentral distance of $5^{\circ}$ from the OPS network. We use the spectral element method [SEM, Komatitsch \& Vilotte, 1998] implemented in the Specfem3D_Globe [e.g., Komatitsch \& Tromp, 2002a,b] to conduct pointsource simulations with periods accurate down to $T=1.6 \mathrm{~s}$ using the global CMT catalog solution for this event [Dziewonski et al. , 1981; Ekström et al. , 2012]. We parameterize Earth structure based on the 3-D crustal model CRUST2.0 [Bassin et al. , 2000], combined with the mantle model S40RTS [Ritsema et al. , 2011]. Earth topography and ellipticity, as well as seismic attenuation are taken into account.

Raw data are converted into ground velocity and a broad pre-filter (0.2 s-200 s) is applied during instrument-response deconvolution to avoid long-period wave-energy amplification. We limit our analysis to the vertical and transverse components because the SEM simulation could not adequately reproduce the radial component (probably because of the unmodeled finite-source effects still visible at short period and at regional distances).

We find consistent time delays $(\Delta t \sim 2 \mathrm{~s})$ between synthetic waveforms and data for all stations. Considering the small inter-station distance $(8-15 \mathrm{~km})$ compared to the distance between the earthquake and the OPS network, this confirms that station clocks worked properly during the entire deployment period. We attribute this $\Delta t$ to the uncertainty in origin time and unmodeled Earth structure.

In the following, we use the ratio of maximum amplitudes between data and synthetics $\left(A r=\max \left[A_{\text {data }}\right] / \max \left[A_{\text {syn }}\right]\right)$ and visual comparisons to further assess the quality of our data. 
When discussing $A r$ of the OPS network, we refer to the median value among all stations for a given wave period. We use the maximum amplitude to verify data conversion from counts to displacement and to estimate local site effects that may potentially affect our seismicity study.

Analysis of low-pass filtered waveforms at $\mathrm{T}=5 \mathrm{~s}$ for the OPS network shows good waveform similarity (Figure 3c) on both the vertical and horizontal components. The modeled amplitudes also fit the data well: $A r$ for the vertical component is $A r_{Z}=1.05$ and for the transverse is $A r_{T}$ $=0.91$ (Figure $3 \mathrm{~b}-\mathrm{c}) . A r$ are similarly good at least up to $\mathrm{T}=10 \mathrm{~s}$ (not shown for brevity). For $\mathrm{T}<5 \mathrm{~s}, A r$ increases as $\mathrm{T}$ decreases suggesting an amplification phenomenon that we attribute to local site effects. These strong site effects are probably due to the fact that, as described in section The OPS network, most sensors were inevitably installed within loose soil.

Larger amplitudes at $\mathrm{T}=2 \mathrm{~s}$ on the OPS transverse components (Figures 3d), compared to the simulations, suggests that we may overestimate the local magnitude (ML) of seismicity recorded on the OPS network. In fact, $\log 10\left(A r_{T}\right)=\log 10\left(A_{\text {Tdata }}\right)-\log 10\left(A_{\text {Tsyn }}\right)$ corresponds to the difference between the ML calculated from observed wave amplitudes $\left(A_{\text {Tdata }}\right)$ and ML calculated from amplitudes of synthetic waveforms $\left(A_{T s y n}\right)$. Therefore, the amplification value of $A r_{T}=1.69$ (at $2 \mathrm{~s}$ ), due to local site conditions, corresponds to an ML overestimation of $\sim 0.23$. Moreover, it cannot be excluded that the amplification can even be higher at $\sim 1 \mathrm{~s}$ at which ML is usually calculated, because amplification increases with decreasing wave period (Figure 3b). Note that a simulation at $\mathrm{T} \sim 1 \mathrm{~s}$ was not possible due to code instability at such short period.

\section{PERFORMANCE OF THE OPS NETWORK AND ITS AMBI- ENT SEISMIC NOISE}

From continuous seismic recordings, probabilistic power spectral densities (PPSD) for each station provide valuable information to assess the performance of the instrument and to extract important features of ambient seismic noise. We use the method of McNamara \& Buland [2004] implemented in the seismology toolbox ObsPy [Beyreuther et al. , 2010; Krischer et al. , 2015] to calculate PPSD's for the OPS data.

For all stations and seismogram components (vertical, north-south, east- west), a PPSD is computed as the statistical distribution of wave amplitudes, for each wave-period, calculated using one-hour long time windows that overlap by $50 \%$. To obtain the statistical distribution, 
each one-hour window is subdivided into segments of 15 minutes (with $75 \%$ overlap). For each waveform segment, a fast Fourier transform is performed, instrument response is removed, and the units are converted to $\mathrm{dB}$ with respect to acceleration. The power of the amplitude spectrum for each 1-hour window (PSD) is then calculated as the smoothed average power of amplitude spectra all 13 time segments. Finally, the PPSD is calculated as the frequency distribution of the PSD at each wave-period.

As an example, Figure 4a shows the vertical-component PPSD at station CES06. The new low-noise model (NLNM) and the new high-noise model (NHNM) [Peterson, 1993] are included defining lower and upper boundaries of seismic noise amplitudes expected at the Earth's surface. The PPSD for the two horizontal components are very similar to each other, at all OPS stations (see supplementary figure S1). Thus, for brevity we will discuss the north- south component only. From the PPSD we will consider the median (called noise level henceforth for simplicity) corresponding to the most frequent amplitude value for each wave-period (Figure 4a). In the supplementary figure S1, we also show the PPSD for the closest permanent station KMBO, located in Kenya, for comparison with our temporary sites.

In general, the trend of the noise level is both affected by station performance (i. e., quality of sensor, burial depth and insulation of sensor, atmospheric effects on location) and ambient seismic noise. Periodic oscillations of noise levels are observed for all temporary and permanent seismic stations around the world [e.g., Stutzmann et al. , 2000; Evangelidis \& Melis, 2012; Custodio et al. , 2014]. These oscillations give insight into the origin of local and remote sources of seismic noise. Since the performance of the station and the ambient seismic noise are two factors often interconnected, we describe them together in terms of noise levels.

The noise levels at the 17 OPS stations (calculated for the entire experiment duration) are displayed in Figures 5b-c. These suggest that the OPS network performed generally very well. The noise levels on the vertical components $(\mathrm{V})$ are good as they fall right between the NHNM and NLNM curves (Figure 4b). However, the long-period noise levels on the horizontal components $(\mathrm{H})$ are larger than the NHNM at some OPS stations.

In particular, $\mathrm{V}$ and $\mathrm{H}$ noise levels are highly variable between OPS stations for wave-periods $\mathrm{T}<1$ s due to anthropic and localized noise sources (e.g., proximity to main roads for CES01, CES10, CES16; a highly populated Maasai village near CES07; proximity to electric tower for CES17). Daily variations of the $\mathrm{V}$ and $\mathrm{H}$ noise levels for $\mathrm{T}<1 \mathrm{~s}$ confirm the anthropic origin 
(see Figure 4d-e). In fact, stations closer to roads and tracks have the largest variations (up to $20 \mathrm{~dB}$ ). Moreover, we observe an increase in noise levels at $\mathrm{T}=0.2-0.7 \mathrm{~s}$ (less than 10 dB) during Autumn (March-May) that may be related to seasons of heavy rain (Figures 5f-g). Rain-generated noise was already observed at similar periods by Ashokan et al. [2015].

$\mathrm{V}$ and $\mathrm{H}$ noise levels in the range of $\mathrm{T}=1-11 \mathrm{~s}$ (microseisms at roughly the secondary period range) are good and similar for all stations, reflecting common remote sources of noise, likely originating from the southern Indian Ocean and southern Atlantic Ocean [Davy et al. , 2015]. In the same period range, OPS stations display an increase in noise levels (less than 4 $\mathrm{dB}$ ) during the southern hemisphere Winter (June-August) (Figures 5g). Although this is an expected behaviour [Stutzmann et al. , 2000; Davy et al. , 2015], this variation is smaller (a few dB) than generally observed (e.g. 10-15 dB) [e.g., Evangelidis \& Melis, 2012; Custodio et al. , 2014] and it does not display the shift of the peak toward longer periods [Stutzmann et al. , 2000]. This is likely due to the large distance from the main noise sources $(>4000 \mathrm{~km})$. No daily variations are observed in the range of $\mathrm{T}=1-11 \mathrm{~s}$.

High variability of $\mathrm{V}$ and $\mathrm{H}$ noise levels among the OPS stations for $\mathrm{T}>11 \mathrm{~s}$ can be explained by local weather conditions (e.g., wind and temperature) that strongly fluctuate between night and day in some locations, resulting in ground tilting of different amplitude [e.g., de Angelis \& Bodin, 2012] and temporarily compromising the performance the stations. For example, the noise level at $\mathrm{T}=40 \mathrm{~s}$ at CES04 changes from night to day (Figure 4d), while at CES05 the noise level in the same period range is non-periodic (Figure 4e). Although differences in long-period noise levels between stations with small inter-distance might be surprising, Dybing et al. [2019] found that even wind-induced seismic noise may be different among close-by stations because of local-scale wind-field heterogeneity due to diurnal heating, topography, and other surface effects. Moreover, variations in soil properties between OPS sites (larger amount of clay on the volcanic highlands, larger amount of sand in the Olduvai basin) may also affect the wind-ground coupling [Wolin et al. , 2015].

As expected, tilting is more evident on the horizontal than on the vertical component (Figure 4c). In fact, the horizontal components on CES01, CES02, CES03, CES10, CES15 and CES16 shown by the $\mathrm{H}$ noise being higher than the NHNM for $\mathrm{T}>11$. However, this is commonly seen in many temporary deployments because of the lack of a proper isolated vault. In addition, we find that the $\mathrm{H}$ tilting is not only due to local conditions, as observed for the vertical noise 
levels, but it can also be due to the instrument itself. The example of temporal variation in Figures $4 \mathrm{f}-\mathrm{g}$ shows that long period $\mathrm{H}$ noise levels decreased during the experiment. This is observed for almost all stations and suggests that the used sensors may require months before properly recording horizontal motions. Seasonal variations in noise levels at long periods $(\mathrm{T}>$ $11 \mathrm{~s}$ ) are not observed (Figures 5f) when considering the entire two years of recordings.

\section{APPROXIMATE THICKNESS OF THE SEDIMENTARY COV- ERS ESTIMATED FROM THE PPSD}

An anomalous peak of high amplitude in the PPSD at $\mathrm{T}=1-2 \mathrm{~s}$ is observed on the horizontal component of some OPS stations (e.g. Figures 5a-c). On the vertical component, the peak is only mildly developed. We exclude that these peaks are due to local sources of noise because no directionality is observed. Therefore, we interpret this peak as amplification of surface waves due to low seismic velocities below the station.

In a first step, for each station, we calculate the parameter $R_{N}=\max \left(N_{T_{1-2 s}}\right) / \max \left(N_{T_{3-10 s}}\right)$, representing the ratio between maximum noise levels in the two period ranges $\mathrm{T}=1-2 \mathrm{~s}$ and $\mathrm{T}=3-10 \mathrm{~s}$ (see Figures $5 \mathrm{a}-\mathrm{d}$ ). We could not use the absolute value of $\max \left(N_{T_{1-2 s}}\right)$ because it is not always representative of the observed PPSD peak at T 1 s. Instead, we include $\max \left(N_{T_{3-10 s}}\right)$, because this period range exhibits noise levels with similar trends for all stations, and hence its maximum value serves as useful reference for each station.

In a second step, we select the stations with $R_{N}>1$ (Figure 5e) and for these we obtain a firstorder approximation of the sedimentary thickness $H$ below the station at which amplification is observed by using the well-known relation between the resonance frequency and sediment thickness valid for a simple 2-layer geological model, $1 / T_{\max }=V s / 4 H$ (Figure $5 \mathrm{~d}$ ). Here, $T_{\max }$ is the wave-period within $T_{1-2 s}$ at which the noise level is the highest and $V s$ is the shear wave speed of the sedimentary layer (see Figures 5a-c for a graphical description). We use $V p=$ $1257 \mathrm{~m} / \mathrm{s}$, calculated from the mean $V p$ in the basin imaged by Lu et al. [2019] and using the reference value $V p / V s=1.75$.

We calculate the associated uncertainty in $H$ due to possible errors in the picking of $T_{1-2 s}$ as $T_{\max }$ is not a single value but rather a range of periods. Whilst the thickness calculations are highly sensitive to the picking of $T_{\max }$, the thickness values obtained for a realistic range of 
Vs does not add further uncertainty. The uncertainties for $H$ range from 25 to $50 \mathrm{~m}$ and are shown in Figure 5e.

It is important to emphasize that $H$ is not inverted from amplitude ratios between horizontal and vertical components, but simply calculated from the $T_{\max }$ for stations in which $R_{N}>1$, that is, for stations with anomalous horizontal amplitudes within the range $T_{1-2 s}$. Therefore, the vertical component is not actually used.

The geographical distribution of large $R_{N}>1$ corresponds to those areas with thick sedimentary covers. CES17 is located at the edge of Eyasi lake on a stack of partially consolidated lacustrine sediments. CES05 and CES07 are located on top or at the edge of the Olbalbal depression that is filled by alluvial fans created by running water during rainy seasons. CES08 and CES11 likely mark the minimum extension of the Olduvai paleolake.

The thickness estimates are reported in Figure 5e. For the Olduvai basin, we estimate that its thickness varies from 370 \pm 50 (at CES11) m to $530 \pm 50 \mathrm{~m}$ (at CES08) (Figure 5d-e). These values are in excellent agreement with the results of Lu et al. [2019] ( 425 m) and with the suggestion of [Ashley \& Hay, 2002] that the thickness of the basin increases from west to east. This suggests that this simple approach, based on station-specific PPSD's for sites inside a sedimentary basin, provides reliable estimates of sedimentary thicknesses. In this study we use PPSD calculated for a long recording time (between 9 and 23 months), however, it is conceivable that even shorter-duration recordings can be used depending on the noise variability in the period of amplification.

\section{SEISMIC ACTIVITY IN THE NCA}

\section{Earthquake locations}

We use the OPS continuous data to analyze the seismicity in the NCA. Earthquakes recorded by the network are detected by applying an STA/LTA (Short Time Average / Long Time Average) algorithm in the frequency band 1-15 Hz. During the 23 months of OPS-operation, more than 2500 events are identified, most of them occurring in the EAR. Given our station distribution, these events cannot be reliably located, and hence are not further analyzed here. Waveforms of detected earthquakes are visually inspected to identify local earthquakes, that is, events likely to have occurred within the OPS network based on differential P and S arrival-times and coda-wave 
duration.

In a first step, $\mathrm{P}$ and $\mathrm{S}$ arrival-times of 118 local earthquake are manually picked and inverted using Hypoinverse [Klein, 2007] to locate the events. We used a $V_{p}$ structural model obtained by applying a $\mathrm{Vp} / \mathrm{Vs}=1.75$ to the average shear wave velocity profile for the entire Tanzanian craton from O'Donnell et al. [2013] (Figure 6f). In a second step, we apply the double-difference (DD) algorithm [Waldhauser \& Ellsworth, 2000] to relocate earthquakes. Also, we test the sensitive of earthquake locations to the velocity model by defining 16 different $V_{p}$ realizations obtained by varying $\mathrm{Vp}$ and the $\mathrm{Vp} / \mathrm{Vs}$ ratio and maintaining the number and thickness of the layers constant. We vary $\mathrm{Vp}$ up to $\pm 10 \%$ and $\mathrm{Vp} / \mathrm{Vs}$ from 1.6 to 1.9. The double-differences are calculated from travel-times only, and inverted applying a singular value decomposition (SVD) method, which provides proper location-error estimates. For each earthquake, we select the location with minimum RMS residual among the 16 calculated. In most of the cases, the optimal $\mathrm{Vp}$ model is in fact the initial model, while $\mathrm{Vp} / \mathrm{Vs}$ ranges from 1.7 and 1.8. This strategy compensates for a missing 3D velocity model, and accounts for the variations in Earth structure for different event-site ray paths.

After relocation, the average horizontal and vertical errors are $780 \mathrm{~m}$ and $680 \mathrm{~m}$, respectively. The differences in location among the 16 DD models are on the same order of these errors. From the first location, applying Hypoinverse and a single velocity model, to the best location selected from the DD locations, the hypocenters shifted on average of $320 \mathrm{~m}$ horizontally and $370 \mathrm{~m}$ vertically. Therefore, the earthquakes are stably located (with small errors), resulting from an accurate manual picking.

Most of the earthquakes in the NCA are located west of the Lemagrut fault (Figure 6a), in the southeastern part of the OPS network, and below the western rim of the Ngorongoro caldera. The depth distribution of hypocenters is bimodal, with peaks at $15 \mathrm{~km}$ and $25 \mathrm{~km}$ (Figure 6d). Shallower earthquakes (depth $<20 \mathrm{~km}$ ) occur east of the First and Lemagrut faults, whereas deeper earthquakes $($ depth $>20 \mathrm{~km}$ ) are detected in the southern part of NCA (Figure 6a-c). No swarm-like events are found in this study.

\section{Earthquake magnitudes}

We calculate local magnitude $\mathrm{M}_{L}$ of the relocated events using the largest amplitude of the two horizontal components and the distance correction proposed by Langston et al. [1998] which was 
obtained for seismicity recorded by a broadband seismic network located just south of our study area. $\mathrm{M}_{L}$ of the events recorded by the OPS network ranges from 0.4 to 3.2 ; the corresponding magnitude-frequency distribution shown in Figure 6e. We compute the magnitude of completeness Mc as the point of maximum curvature of the frequency-magnitude curve [Woessner \& Wiemer, 2005], finding $\mathrm{Mc}=1.6$ for this data set. As reference, nearby seismic experiments [Albaric et al. , 2014; Weinstein et al. , 2017] reported $M c=2.1$ and $M c=1.05$, respectively. The Mc value for the OPS network may appear high considering the small inter-station distances $(8-15 \mathrm{~km})$. However, it is important to note that our $\mathrm{M}_{L}$ values are likely to be overestimated by about $\sim 0.23$ due to amplification on the horizontal component for most of the stations (see previous section on the Validation of the OPS dataset). Also, most of the seismicity is located at the edge of the OPS network and artificially increases Mc [Schorlemmer \& Woessner, 2008]. Finally, the fact that most of the seismicity is located in the south part of the network, where two noisy stations are located (CES01 and CES10; Figure 4b-c for $\mathrm{T}<1 \mathrm{~s}$ ) may contribute to a relatively higher Mc estimate.

The slope of the magnitude-frequency distribution yields a b-value of 0.72 (Figure 6e), calculated with the maximum likelihood estimation method [Aki, 1965]. This b-value is lower than the values obtained by Langston et al. [1998] $(\mathrm{b}=0.84)$ and Weinstein et al. [2017] $(\mathrm{b}=0.87)$ for nearby study areas. However, the limited number of earthquakes in our catalogue may affect our b-value estimate.

\section{Focal mechanisms}

Next, we calculate double-couple focal mechanisms by inverting P-wave polarities applying the algorithm of Hardebeck \& Shearer [2002] and the starting model used for earthquake location. Unfortunately, only two earthquakes are recorded with an azimuthal gap of less than $90^{\circ}$. The best models for these two events are shown in $7 \mathrm{a}$.

\section{Analysis of earthquake clusters}

Through 3-D visual inspection of the seismicity we subdivided the relocated earthquakes in four clusters that correspond to different tectonic elements. We assign a letter and a color to proceed with the description. From north to south, the clusters are: O-yellow, C-purple, L-green and S-red (Figure 7). 
The O-yellow cluster includes earthquakes dotting the Olduvai plain and the Olbalbal depression (Figure 7, map and section OO'). An earthquake of this cluster occurred at a depth of $7 \mathrm{~km}$ ca, on a nearly vertical fault (dashed line in the corresponding vertical section, Figure 7b), as shown by the focal mechanism. The fault mechanism and location of this $\mathrm{M}_{L} 2.4$ earthquake suggests that this event may have occurred on the Third or Second fault. All other earthquakes of this cluster occur on the First/Second/Third fault systems with hypocentral depth less than $\sim 17 \mathrm{~km}$

In Figure 7 we also plot an Mb 4.5 event that occurred August 5, 2018 (just after the OPS experiment). Unfortunately, it was not possible to calculate its focal mechanism with publicly available data. Some of the events of O-yellow cluster, together with this teleseismic earthquake, may fit a steep fault dipping WNW whose surface projection correspond to the Meshili fault which separate the NVH from the Olbalbal depression. Another set of events are located in the Olbalbal depression, however, no earthquakes are located in the area of the previously proposed Olduvai paleolake. Therefore, the most active fault of the Olduvai plain is the Meshili fault, which manifests itself also by the presence of the Olbalbal depression.

The C-purple cluster includes events located below the Ngorongoro caldera (Figure 7, map and section $\left.\mathrm{CC}^{\prime}\right)$. The depth distribution ranges between about 5 and $20 \mathrm{~km}$, and traces a listric fault whose surface projection correspond to the NW caldera rim and associated faults. C-purple earthquakes do not cluster in time, and their seismic signals do not significantly differ in spectral characteristics from other events recorded by the OPS network. Earthquakes located showing a similar spatial arrangement are shown by Weinstein et al. [2017], but their depth range is wider (about $7-30 \mathrm{~km}$ ).

A few earthquakes, located between the extinct Lemagrut volcano and the Ngorongoro crater rim, are assigned to the L-green cluster, aligned along a fault dipping toward east (Figure 7, map and section LL'). The surface projection of this listric fault corresponds to a visually prominent fault crossing the Lemagrut volcano (in north-south direction); the fault appears to flatten at $20 \mathrm{~km}$ depth. At this stage it is not known if the Lemagrut fault is a southern prolongation of the First fault or northern prolongation of the Eyasi fault [Le Gall et al. , 2008], but it appears to be currently more active than the other two faults.

The S-red cluster includes most of the seismicity recorded during the OPS experiment (Figure 7, map and section SS'). It is located below the villages Laetoli and Endulen (Figure 2a) and 
extends across the Eyasi fault. These events align along a WNW-ESE strike, dipping $45^{\circ}$ towards NNE (Figure 7, section SS'). These events are concentrated in the depth range of 15 to $30 \mathrm{~km}$ depths. However, it is possible that shallower earthquakes occur, but are not recorded by the OPS network because of its limited extension.

Hypocentral depths, especially for deep earthquakes, depend on the Vp/Vs ratio. RMS residuals for the S-red cluster are the lowest for $\mathrm{Vp} / \mathrm{Vs}$ between 1.7 and 1.8. For the S-red cluster, the average depths for $\mathrm{Vp} / \mathrm{Vs}$ between 1.7 and 1.8 ranges between $\sim 18$ and $\sim 20 \mathrm{~km}$. On the other hand, the DD depths vary few hundreds of meters for the same range of Vp/Vs. Therefore, the depth distribution of the S-red cluster is overall reliable. Deep earthquakes, as the ones observed in the S-red cluster, are were previously observed in the Tanzanian craton [Nyblade \& Langston, 1995; Albaric et al. , 2009; Craig et al. , 2011; O’Donnell et al. , 2015]. They are presumably due to thermal anomalies that lead to lower crustal seismicity [e.g., Nyblade \& Langston, 1995; Albaric et al. , 2009] and O'Donnell et al. [2015] found that even gravitational forces due to uplift may play a role.

The focal mechanism for an $\mathrm{M}_{L} 2.2$ earthquake belonging to the S-red cluster (Figure 7) shows normal-fault mechanism. One of the focal planes is dipping $\sim 40^{\circ}$ towards NNE, in agreement with the orientation of the tectonic feature depicted by the entire cluster. In addition, an Mw 5.5 earthquake occurred on May 15,1990, in proximity of the S-red cluster, with similar faulting mechanism. The orientation of these focal planes are not optimally oriented for the E-W/ESE-WNW current regional stress [e.g., Albaric et al. , 2010; Weinstein et al. , 2017]. Therefore, it is plausible that slip occurs along a pre-rift shear zone. Smith \& Mosley [1993] found that pre-existing NW-SE shear zones along the Tanzanian craton margin are prone to reactivation during the current rifting stage.

The surface projection (dashed line in map of Figure 7) of the tectonic feature depicted by these earthquake crosses the Eyasi fault $\sim 15 \mathrm{~km}$ from the southernmost station of the OPS network. Moreover, the surface projection corresponds to the locality where the boundary between the Tanzanian craton and the Mozambique belt outcrops at the surface [Foster et al. , 1997] and it is estimated to dip $45^{\circ}$ [Ebinger et al. , 1997], similarly to the tectonic feature depicted by the S-red cluster.

The geographical location and its depth extent, as well as the strike and dip of this tectonic feature, suggest that the S-red cluster could depict the suture between the Tanzanian craton 
and the Mozambique belt that has been reactivated to accommodate the current regional stress.

\section{TECTONICS OF THE WESTERN FLANK OF THE NTD}

The OPS network covers all NCA, thereby complementing previous seismic experiments in the area and facilitating a better understanding of the NTD. In the Olduvai basin, the OPS network slightly overlaps with a recent experiment [Weinstein et al. , 2017] that aims at investigating the rift region, however, our network is denser and also covers the southern part of the NVH. Another seismic network in the area by Albaric et al. [2010] had slightly less dense coverage in the southern NVH; their study did not report any seismicity in the southern part of the NVH that was detected by our OPS network. We argue that these earthquakes represent background seismicity, and do not occur as swarm-like seismicity. However, the higher Mc and the short duration of their experiment may have prevented them from mapping seismicity located north of Eyasi lake. As expected from reviewing the ISC catalogue (Figure 1), the OPS experiment documents that seismicity is sparse in the NCA. However, the small array dimensions of the OPS network allows us to depict minor faults located in the rift flank and a major tectonic feature that was not revealed until now.

In the Olduvai plain, no earthquakes are recorded east of the First/Second/Third fault system (Figure 6). This suggests that the main faults that created the accommodation space in the Olduvai paleolake are currently aseismic. Three OPS stations (CES06 CES08 and CES11) are located in proximity of the detected location of the paleolake. Horizontal-component ambient noise for two of these stations (CES08 and CES11), amplified in the period range $\mathrm{T}=1-2 \mathrm{~s}$ (Figure 5), allows us to estimate the thickness of sedimentary strata below the stations. We obtain values of $370 \pm 50 \mathrm{~m}$ and $530 \pm 50 \mathrm{~m}$ at stations CES11 and CES08, respectively. These results confirm that sedimentary thickness of the Olduvai paleolake increases from west to east, as postulated by Ashley \& Hay [2002], confirming that the main stream of sediments was arriving from the NVH. Our thickness values are consistent with a recent active seismic experiment [Lu et al. , 2019] that proposed a sedimentary record at Olduvai of $\sim 425 \mathrm{~m}$, at least $200 \mathrm{~m}$ deeper than previously inferred, suggesting that the development of the basin may have begun already 4 Ma ago [Lu et al. , 2019]. However, the investigations of Lu et al. [2019] and Stanistreet et al. [2020a] were limited to the Fifth fault on the west and to the gorge on the east. The larger 
scale of our experiment allows us to reveal the depth of the paleolake below CES11, located west of the Fifth fault, and CES08, located SE of the intersection between the two branches of the gorge.

In contrast to the Olduvai paleolake, the Olbalbal depression currently accumulates sediments from east and west, and comprises an ephemeral lake in its northern part during rainy seasons (Figure 2). The Olbalbal depression started to develop at least $\sim 1.81$ Ma [Stollhofen \& Stanistreet, 2012] ago, and became a more prominent feature of the Olduvai basin $\sim 0.8$ Ma [Stanistreet et al. , 2020a] ago when the paleolake Olduvai shrank within its hosting sub-basin. By that time, the volcanoes of the NVH were no longer as efficiently filling the developing Olbalbal, while the rifting of the EAR and extension along the First and Meshili faults continued. It was this change that prompted the reversal of regional drainages from westward to eastward [Stanistreet et al. , 2020a] directed flow, leading to the present situation in which the Olduvai River drains into the Olbalbal depression. Our analysis of seismic-wave amplifications reveals that stations near the edge of the depressions (CES07 and CES05) in the Olbabal are underlain by sedimentary strata with thickness ranging from $580 \pm 50 \mathrm{~m}$ to $630 \pm 25 \mathrm{~m}$ (Figure 5). These values correspond to an average sediment accumulation rate of $0.53 \pm 0.05 \mathrm{~mm} /$ year.

Seismic activity recorded on the Meshili fault, suggests that this fault is currently responsible for creating the accommodation space in the Olbalbal depression (Figures 5, 7 and 8). We estimate that the Meshili fault is a steeply NW-dipping fault able to generate earthquakes of at least magnitude 4.5 (recall the event of August 5, 2018). A few Masaai villages at the western edge of the Olbalbal depression are potentially exposed to earthquake-triggered rock falls from the western slopes of the NVH, and should be informed correspondingly. Our network also recorded an $\mathrm{M}_{L} 2.4$ on a steep ESE-dipping normal fault on the First/Second/Third fault system. Additional events located in the Olbalbal depression lead us to speculate that these earthquakes occur on faults synthetic to the rift bounding faults that contribute (together with the Meshili fault) to create the accommodation space for the Olbalbal depression (Figures 7 and $8)$.

We also recognized two synthetic listric faults, the NWR (dipping SE) and Lemagrut (dipping E) faults, that run in the vicinity of the Ngorongoro and Lemagrut rims. Stollhofen \& Stanistreet [2012] speculated that the First fault system may act as a decollement below the NVH, possibly joining the rift bounding faults to the east. Our data suggest that the Lemagrut and NWR faults 
may join such decollement, located at $\sim 20 \mathrm{~km}$ depth, where these two faults flatten (Figures 7 and 8$)$.

Interestingly, the geologically prominent Eyasi fault appears aseismic, as we do not record any seismic activity directly related to it. In fact, catalogue data (Figure 1) and previous seismic experiments [Nyblade et al. , 1996; Albaric et al. , 2010; Weinstein et al. , 2017] do not report any significant activity along the rift-bounding Eyasi fault. However, we do detect a seismically active, NNE-dipping fault that cuts across the Eyasi fault (Figures 7 and 9). While the seismogenic zone below the eastern NHV and the Olduvai basin is confined to the upper $20 \mathrm{~km}$, this newly detected fault reaches $30 \mathrm{~km}$ depth. We argue that this structure represents the suture zone between the Tanzanian craton and the Mozambique belt, whose location is still considered uncertain [Ebinger et al. , 1997], but which here we have mapped at depth explicitly for the first time. Foster et al. [1997] report the outcrop of such a boundary north of Lake Eyasi, and map it at about the same location where the projection of our inferred suture zone occurs. Moreover, Ebinger et al. [1997] estimate that at this location the suture should dip at about $45^{\circ}$ which corresponds to the dip angle of the fault inferred from our recorded seismicity (Figures 7 and 9).

The (re-)activation of pre-existing NW-SE structures within and along the Tanzanian craton is reported by Smith \& Mosley [1993], being a consequence of the current local NW-SE extension [Weinstein et al. , 2017; Albaric et al. , 2014; Ibs-von Seht et al. , 2001] in the NTD. If this structure is interpreted as a transform fault connecting the Natron rift to the Manyara branch, the slip on the suture should be left-lateral. However, the focal mechanisms (Figures 7 and 9) rather suggest normal-faulting motion. Two possible explanations are: i) the suture is not steep enough to accommodate strike-slip motion, or ii) strike-slip faulting occurs but our observations are limited. An alternative explanation is that the local extension direction is NE-SW, at least in the southern-central NTD, as shown by some focal mechanisms along the Engaruka transform fault [Weinstein et al. , 2017]. The Engaruka fault (located north of the Manyara fault) is, in fact, similarly oriented to the seismically active suture zone, suggesting that both may be affected by the same regional stress. It is important to note that earthquakes on the suture zone may be able to generate magnitude 5.5 earthquakes (recall the event of May 15, 1990). In particular, the world-known archeological site of Laetoli and its related museum, and the village of Endulen are located on the footwall of the fault. Thus, local authorities should be informed 
about the possibility of sizable earthquakes occurring on this seismogenic zone.

Tectonically, strain release on the suture may limit the seismic activity on the Eyasi fault. In fact, the eastern part of the Eyasi fault does not show any current seismic activity despite its optimal orientation with respect to the current regional stresses (Figures 7 and 9). The riftbounding Eyasi fault is mostly located within the thick and lithosperically strong Tanzanian craton crust which appears to be faulted only down to a few $\mathrm{km}$ depth [Ebinger et al. , 1997]. Therefore, the current NW-SE oriented regional stress is probably more effectively accommodated by the pre-existing and deeply penetrating discontinuity represented by the boundary between the Tanzanian craton and the Mozambique belt.

In this context we remark that from the Mesozoic onwards, the extension direction rotated clockwise [Smith \& Mosley, 1993], and thus the suture might have undergone oblique-extension, facilitating magmatic ascent that fed Lemagrut and Saliman volcanoes during the late Pliocene [e.g., Mollel et al. , 2011] that are aligned with the surface projection of deep-seated parts of the suture (Figure 9).

Our proposed model also helps to shed light on the occurrence of deep earthquakes often observed in eastern Africa [Albaric et al. , 2009; Nyblade \& Langston, 1995; Craig et al. , 2011, e.g., ]. Previous studies explained hypocentres deeper than $30 \mathrm{~km}$ with the presence of strong mafic crust [Albaric et al. , 2009; Nyblade \& Langston, 1995]. In our study, the mafic composition of the crust could be explained by Pliocene volcanism that may have favorited dyke and sill swarms along and at the bottom of the suture. However, in most of the cases, a mafic crust is not sufficient to justify such hypocentral depths and, therefore, complicated heat models [Nyblade \& Langston, 1995] and fluid compositions are invoked [Craig et al. , 2011]. Moreover, O'Donnell et al. [2015] showed that, in case of lack of melt, the rupture of a thick and strong mafic crust under the current stress in Africa is highly unlikely. On the other hand, Fagereng [2013] showed that while a shallow seismogenic zone $(<12 \mathrm{~km})$ (as the one of the Lemagrut and Eyasi faults) can exist in a strong thick crust, a deep seismogenic zone ( $>30 \mathrm{~km})$ can develop only when relevant pre-existing weaknesses are present (as along the suture zone). Thus, the pre-existing suture and the oblique extension during the Pliocene can explain the current deep seismic activity. 


\section{CONCLUSIONS}

In this study, we present the OPS dataset consisting of three-component broadband continuous seismic recordings (frequency range $0.01-100 \mathrm{~Hz}$ ) acquired at 17 sites installed on the western flank of the NTD between June 2016-May 2018.

We analyze ambient noise levels and conduct seismic wavefield simulations to evaluate the reliability of the OPS dataset and to identify potential pitfalls. We believe that such quality control should always be performed for any temporary passive seismic experiment. We found that the OPS dataset is of good quality and our rigorous analysis allows us to highlight an overestimation of, at least, $\mathrm{M}_{L} 0.23$ due to the loose sedimentary material in which the sensors were buried.

A detailed PPSD analysis shows that while seasonal oscillations of secondary microseismic noise are smaller than for most sites globally, long period ambient noise ( $\mathrm{T}>10 \mathrm{~s}$ ) at temporary sites can be highly variable within even small distances due to installation settings and local weather conditions. Wave periods at which local earthquakes are recorded $(\mathrm{T}<1 \mathrm{~s})$ can be noisy even in remote regions as the NCA, because the requirement of safe sites often favors locations near human settlements.

We also show how a simple quantitative analysis of noise levels provides first-order information on soft-layer thickness below a seismic station; we use these thickness estimates to obtain constrains on the lateral extension and depth of the paleolake Olduvai, Obalbal depression and the northern edge of lake Eyasi.

The OPS dataset also allows to generate an NCA seismicity map of unprecedented detail, because of the small array aperture of the experiment and accurate earthquake arrival-time picking. Our seismicity images depicts, for the first time, the suture between the Tanzanian craton and the Mozambique belt, which crosses the Eyasi fault and dips NNE. Our seismicity map also shows two listric faults, synthetic to the rift. At depth, these faults appear to merge into a single detachment that originates at the Sixth fault in the Olduvai and joins the the Manyara bounding fault in the main rift valley.

Although the seismic risk within the NCA is considered low, the hazard related to the Meshili fault and the suture shear zone should not be ignored, because these may generate earthquakes of magnitude $\sim 5$ and above. 


\section{Data and resources}

Data collected during the OPS experiment can be requested to the first author. The supplementary figure S1 shows PPS for the three component of the seismograms for two OPS station and the KMBO permanent station. Data for the KMBO station are available from the IRIS Data Management Center at www.iris.edu (last accessed June 2020).

\section{Acknowledgments}

The authors would like to acknowledge the Tanzanian Commission for Science and Technology (COSTECH), the Department of Antiquities, Ngorongoro Conservation Area Authority (NCAA) for research permits. We thank Larau, Luigi Lombardo, Maria Rodriguez-Mustafa, Olaf Zielke, Zheng Tang and Max Mai for their contribution during fieldwork and Rémi Matrau for helping with Figure 9. We extensively used the ObsPy package [Beyreuther et al. , 2010; Krischer et al. , 2015], the database for seismological dataset Jane and ObsPyck used for seismic phase picking developed by Lion Krischer, Robert Barsch and Tobias Megies. GMT tools were used to produce some of the figures [Wessel et al. , 2013]. Finally, we thank the Editor, the Associated Editor and two anonymous reviewers for their detailed and encouraging reviews, which helped improve our manuscript. This work was funded by the KAUST baseline BAS/1/1339-01-01 granted to P. Martin Mai.

\section{References}

Aki, K. 1965. Maximum likelihood estimate of $\mathrm{b}$ in the formula $\log \mathrm{N}=\mathrm{a}-\mathrm{bM}$ and its confidence limits. Bull. Earthquake Res. Inst. Univ. Tokyo,, 43, 237-239.

Albaric, J., Déverchère, J., Petit, C., Perrot, J., \& Le Gall, B. 2009. Crustal rheology and depth distribution of earthquakes: Insights from the central and southern East African Rift System. Tectonophysics, 468(1), $28-41$.

Albaric, J., Perrot, J., Déverchère, J., Deschamps, A., Le Gall, B., Ferdinand, R.W., Petit, C., Tiberi, C., Sue, C., \& Songo, M. 2010. Contrasted seismogenic and rheological behaviours 
from shallow and deep earthquake sequences in the North Tanzanian Divergence, East Africa. Journal of African Earth Sciences, 58(5), 799-811.

Albaric, J., Déverchère, J., Perrot, J., Jakovlev, A., \& Deschamps, A. 2014. Deep crustal earthquakes in North Tanzania, East Africa: Interplay between tectonic and magmatic processes in an incipient rift. Geochemistry, Geophysics, Geosystems, 15(2), 374-394.

Ashley, G.M., \& Hay, R.L. 2002. Sedimentation patterns in a Plio-Pleistocene volca- niclastic rift-margin basin, Olduvai Gorge, Tanzania. In: Renaut, R.W., Ashley, G.M. (Eds.), Sedimentation in Continental Rifts. Soc. Econ. Paleontol. Mineral. Spec. Publ., 73, 107-122.

Ashokan, M., Latha, G., \& Ramesh, R. 2015. Analysis of shallow water ambient noise due to rain and derivation of rain parameters. Applied Acoustics, 88, 114-122.

Bassin, C, Laske, G., \& Masters, G. 2000. The current limits of resolution for surface wave tomography in North America. EOS Trans. AGU, F897, 81.

Beyreuther, M., Barsch, R., Krischer, L., Megies, T., Behr, Y., \& Wassermann, J. 2010. ObsPy: A Python Toolbox for Seismology. Seismological Research Letters, 81(3), 530-533.

Calais, E., Ebinger, C.J., Hartnady, C., \& Nocquet, J.M. 2006. Kinematics of the East African Rift from GPS and earthquake slip vector data. Geological Society Special Publication, 259, $9-22$.

Craig, T. J., Jackson, J. A., Priestley, K., \& McKenzie, D. 2011. Earthquake distribution patterns in Africa: their relationship to variations in lithospheric and geological structure, and their rheological implications. Geophysical Journal International, 185(1), 403-434.

Custodio, S., Dias, N.A., Caldeira, B., Carrilho, F., Carvalho, S., Corela, C., Díaz, J., Narciso, J., Madureira, G., Matias, L., \& Haberland, C. 2014. Ambient noise recorded by a dense broadband seismic deployment in Western Iberia. Bulletin of the Seismological Society of America, 104(6), 2985-3007.

Davy, C., Stutzmann, E., Barruol, G., Fontaine, F.R., \& Schimmel, M. 2015. Sources of secondary microseisms in the Indian Ocean. Geophysical Journal International, 202(2), 11801189. 
Dawson, J.B. 1992. Neogene tectonics and volcanicity in the North Tanzania sector of the Gregory Rift Valley: contrasts with the Kenya sector. Tectonophysics, 204(1-2), 81-83,8792.

de Angelis, S., \& Bodin, P. 2012. Watching the Wind: Seismic data contamination at long periods due to atmospheric pressure-field-induced tilting. Bulletin of the Seismological Society of America, 102(3), 1255-1265. cited By 20.

Deino, A.L. 2012. 40Ar/39Ar dating of Bed I, Olduvai Gorge, Tanzania, and the chronology of early Pleistocene climate change. Journal of Human Evolution, 63(2), 251-273.

Deino, A.L., King, J., McHenry, L.J., Stanistreet, I.G., Stollhofen, H., Toth, N., Schick, K., \& Njau, J.K. 2020, in press. Chronostratigraphy and Age Modeling of Quaternary Drill Cores from the Olduvai Basin, Tanzania (Olduvai Gorge Coring Project). Palaeogeography, Palaeoclimatology, Palaeoecology.

Dybing, S.N., Ringler, A.T., Wilson, D.C., \& Anthony, R.E. 2019. Characteristics and spatial variability of wind noise on near-surface broadband seismometers. Bulletin of the Seismological Society of America, 109(3), 1082-1098. cited By 1.

Dziewonski, A.M., Chou, T.-A., \& Woodhouse, J.H. 1981. Determination of earthquake source parameters from waveform data for studies of global and regional seismicity. Journal of Geophysical Research, 86(B4), 2825-2852.

Ebinger, C., Djomani, Y.P., Mbede, E., Foster, A., \& Dawson, J.B. 1997. Rifting Archaean lithosphere: The Eyasi-Manyara-Natron rifts, East Africa. Journal of the Geological Society, 154(6), 947-960.

Ebinger, Cynthia. 2005. Continental break-up: The East African perspective. Astronomy \& Geophysics, 46(2), 2.16-2.21.

Ekström, G., Nettles, M., \& Dziewonski, A.M. 2012. The global CMT project 2004-2010: Centroid-moment tensors for 13,017 earthquakes. Physics of the Earth and Planetary Interiors, 200-201, 1-9.

Evangelidis, C.P., \& Melis, N.S. 2012. Ambient noise levels in Greece as recorded at the hellenic unified seismic network. Bulletin of the Seismological Society of America, 102(6), 2507-2517. 
Fagereng, A. 2013. Fault segmentation, deep rift earthquakes and crustal rheology: Insights from the 2009 Karonga sequence and seismicity in the Rukwa-Malawi rift zone. Tectonophysics, $601,216-225$.

Foster, A., Ebinger, C., Mbede, E., \& Rex, D. 1997. Tectonic development of the northern Tanzanian sector of the East African Rift System. Journal of the Geological Society, 154(4), 689-700.

Hardebeck, J.L., \& Shearer, P.M. 2002. A new method for determining first-motion focal mechanisms. Bulletin of the Seismological Society of America, 92(6), 2264-2276.

Hay, R.L. 1976. Geology of the Olduvai Gorge. University of California Press, Berkeley.

Ibs-von Seht, M., Blumenstein, S., Wagner, R., Hollnack, D., \& Wohlenberg, J. 2001. Seismicity, seismotectonics and crustal structure of the southern Kenya Rift - new data from the Lake Magadi area. Geophysical Journal International, 146(2), 439-453.

Klein, F. W. 2007. Users guide to HYPOINVERSE-2000, a Fortran program to solve for earthquake locations and magnitudes. U.S. Geol. Surv. Open File Rep., 02-171.

Komatitsch, D., \& Tromp, J. 2002a. Spectral-element simulations of global seismic wave propagation - I. Validation. Geophysical Journal International, 149(2), 390-412.

Komatitsch, D., \& Tromp, J. 2002b. Spectral-element simulations of global seismic wave propagation - II. Three-dimensional models, oceans, rotation and self-gravitation. Geophysical Journal International, 150(1), 303-318.

Komatitsch, D., \& Vilotte, J.-P. 1998. The spectral element method: An efficient tool to simulate the seismic response of 2D and 3D geological structures. Bulletin of the Seismological Society of America, 88(2), 368-392.

Krischer, L., Megies, T., Barsch, R., Beyreuther, M., Lecocq, T., Caudron, C., \& Wassermann, J. 2015. ObsPy: a bridge for seismology into the scientific Python ecosystem. Computational Science \& Discovery, 8(1), 014003. 
Langston, C.A., Brazier, R., Nyblade, A.A., \& Owens, T.J. 1998. Local magnitude scale and seismicity rate for Tanzania, East Africa. Bulletin of the Seismological Society of America, 88(3), $712-721$.

Le Gall, B., Nonnotte, P., Rolet, J., Benoit, M., Guillou, H., Mousseau-Nonnotte, M., Albaric, J., \& Deverchère, J. 2008. Rift propagation at craton margin. Distribution of faulting and volcanism in the North Tanzanian Divergence (East Africa) during Neogene times. Tectonophysics, 448(1-4), 1-19.

Leakey, M., \& Hay, R. 1979. Pliocene footprints in the Laetolil Beds at Laetoli, northern Tanzania. Nature, 317-323.

Leakey, M.D. 1971. Olduvai Gorge: Excavations in Beds I and II, 1960-1963. Cambridge University Press, Cambridge.

Lu, K., Hanafy, S., Stanistreet, I., Njau, J., Schick, K., Toth, N., Stollhofen, H., \& Schuster, G. 2019. Seismic imaging of the Olduvai Basin, Tanzania. Palaeogeography, Palaeoclimatology, Palaeoecology, $\mathbf{5 3 3 .}$

Mana, S., Furman, T., Turrin, B.D., Feigenson, M.D., \& Swisher, C.C., III. 2015. Magmatic activity across the East African North Tanzanian Divergence Zone. Journal of the Geological Society, 172, 368-389.

Masao, F. T., Ichumbaki, E. B., Cherin, M., Barili, A., Boschian, G., Iurino, D. A., Menconero, S., Moggi-Cecchi, J., \& Manzi, G. 2016. New footprints from Laetoli (Tanzania) provide evidence for marked body size variation in early hominins. eLife, $\mathbf{5}(\mathrm{dec})$.

McHenry, L.J., Mollel, G.F., \& Swisher III, C.C. 2008. Compositional and textural correlations between Olduvai Gorge Bed I tephra and volcanic sources in the Ngorongoro Volcanic Highlands, Tanzania. Quaternary International, 178(1), 306-319.

McNamara, D. E., \& Buland, R. P. 2004. Ambient Noise Levels in the Continental United States. Bulletin of the Seismological Society of America, 94(4), 1517-1527.

Mollel, G.F., Swisher, C.C., III, Feigenson, M.D., \& Carr, M.J. 2011. Petrology, geochemistry and age of Satiman, Lemagurut and Oldeani: Sources of the volcanic deposits of the Laetoli area. Vertebrate Paleobiology and Paleoanthropology, 99-119. 
Nyblade, A. A., Langston, C. A., Last, R. J., Birt, C., \& Owens, T. J. 1996. Seismic experiment reveals rifting of craton in Tanzania. Eos, Transactions American Geophysical Union, 77(51), $517-521$.

Nyblade, Andrew A., \& Langston, Charles A. 1995. East African earthquakes below $20 \mathrm{~km}$ depth and their implications for crustal structure. Geophysical Journal International, 121(1), 49-62.

O’Donnell, J.P., Selway, K., Nyblade, A.A., Brazier, R.A., Tahir, N. El, \& Durrheim, R.J. 2015. Thick lithosphere, deep crustal earthquakes and no melt: a triple challenge to understanding extension in the western branch of the East African Rift. Geophysical Journal International, $\mathbf{2 0 4}(2), 985-998$.

O’Donnell, J. P., Adams, A., Nyblade, A. A., Mulibo, G. D., \& Tugume, F. 2013. The uppermost mantle shear wave velocity structure of eastern Africa from Rayleigh wave tomography: constraints on rift evolution. Geophysical Journal International, 194(2), 961-978.

Peterson, J. 1993. Observations and Modeling of Background Seismic Noise. U.S. Geol. Surv. Open File Rep., 93-322.

Reck, H. 1914. Erste vorlaufige Mitteilung uber den Fund eines fossilen Menschenskelets aus Zentralafrika. Ges. Naturforsch. Freunde, 3, 81-95.

Ritsema, J., Deuss, A., Van Heijst, H.J., \& Woodhouse, J.H. 2011. S40RTS: A degree-40 shearvelocity model for the mantle from new Rayleigh wave dispersion, teleseismic traveltime and normal-mode splitting function measurements. Geophysical Journal International, 184(3), $1223-1236$.

Schorlemmer, D., \& Woessner, J. 2008. Probability of detecting an earthquake. Bulletin of the Seismological Society of America, 98(5), 2103-2117.

Smith, M. 1994. Stratigraphic and structural constraints on mechanisms of active rifting in the Gregory Rift, Kenya. Tectonophysics, 236(1-4), 3-22.

Smith, M., \& Mosley, P. 1993. Crustal heterogeneity and basement influence on the development of the Kenya Rift, East Africa. Tectonics, 12(2), 591-606. 
Stanistreet, I.G., Stollhofen, H., Deino, A. L., McHenry, L. J., Toth, N. P, Schick, K. A., \& Njau, J. K. 2020a. New Olduvai Basin stratigraphy and stratigraphic concepts revealed by OGCP cores into the Palaeolake Olduvai depocentre, Tanzania. Palaeogeography, Palaeoclimatology, Palaeoecology.

Stanistreet, I.G., Boyle, J.F., Stollhofen, H., Deocampo, D.M., Deino, A., McHenry, L.J., Toth, N., Schick, K., \& Njau, J.K. 2020b. Palaeosalinity and palaeoclimatic geochemical proxies (elements $\mathrm{Ti}, \mathrm{Mg}, \mathrm{Al}$ ) vary with Milankovitch cyclicity (1.3 to 2.0 Ma), OGCP cores, Palaeolake Olduvai, Tanzania. Palaeogeography, Palaeoclimatology, Palaeoecology, 546.

Stollhofen, H., \& Stanistreet, I.G. 2012. Plio-Pleistocene synsedimentary fault compartments, foundation for the eastern Olduvai Basin paleoenvironmental mosaic, Tanzania. Journal of Human Evolution, 63(2), 309-327.

Stutzmann, E., Roult, G., \& Astiz, L. 2000. GEOSCOPE station noise levels. Bulletin of the Seismological Society of America, 90(3), 690-701.

Waldhauser, F., \& Ellsworth, W.L. 2000. A Double-difference Earthquake location algorithm: Method and application to the Northern Hayward Fault, California. Bulletin of the Seismological Society of America, 90(6), 1353-1368.

Weinstein, A., Oliva, S.J., Ebinger, C.J., Roecker, S., Tiberi, C., Aman, M., Lambert, C., Witkin, E., Albaric, J., Gautier, S., Peyrat, S., Muirhead, J.D., Muzuka, A.N.N., Mulibo, G., Kianji, G., Ferdinand-Wambura, R., Msabi, M., Rodzianko, A., Hadfield, R., Illsley-Kemp, F., \& Fischer, T.P. 2017. Fault-magma interactions during early continental rifting: Seismicity of the Magadi-Natron-Manyara basins, Africa. Geochemistry, Geophysics, Geosystems, 18(10), $3662-3686$.

Wessel, P., W., Smith, H.F., Scharroo R., Luis, J.F., \& Wobbe, F. 2013. Generic Mapping Tools: Improved version released. EOS Trans. AGU, 94, 409-410.

Woessner, J., \& Wiemer, S. 2005. Assessing the quality of earthquake catalogues: Estimating the magnitude of completeness and its uncertainty. Bulletin of the Seismological Society of America, 95(2), 684-698. 
Wolin, E., van der Lee, S., Bollmann, T.A., Wiens, D.A., Revenaugh, J., Darbyshire, F.A., Frederiksen, A.W., Stein, S., \& Wysession, M.E. 2015. Seasonal and diurnal variations in long-period noise at SPREE stations: The influence of soil characteristics on shallow stations' performance. Bulletin of the Seismological Society of America, 105(5), 2433-2452. 


\section{Authors mailing address list}

- Laura Parisi

King Abdullah University of Science and Technology, Thuwal, 23955, Saudi Arabia.

- Ian Stanistreet

Department of Earth, Ocean and Ecological Sciences, University of Liverpool, Jane Herdman Building, 4 Brownlow Street, Liverpool, L69 3GP, UK.

- Jackson Njau

Department of Earth \& Atmospheric Sciences, Indiana University, 1001 E 10th St, Bloomington, IN 47408, United States, USA.

- Kathy Schick

P.O. Box 5097, Bloomington, IN, 47407-5097, USA.

- Nicholas Toth

P.O. Box 5097, Bloomington, IN, 47407-5097, USA.

- P. Martin Mai

King Abdullah University of Science and Technology, Thuwal, 23955, Saudi Arabia. 


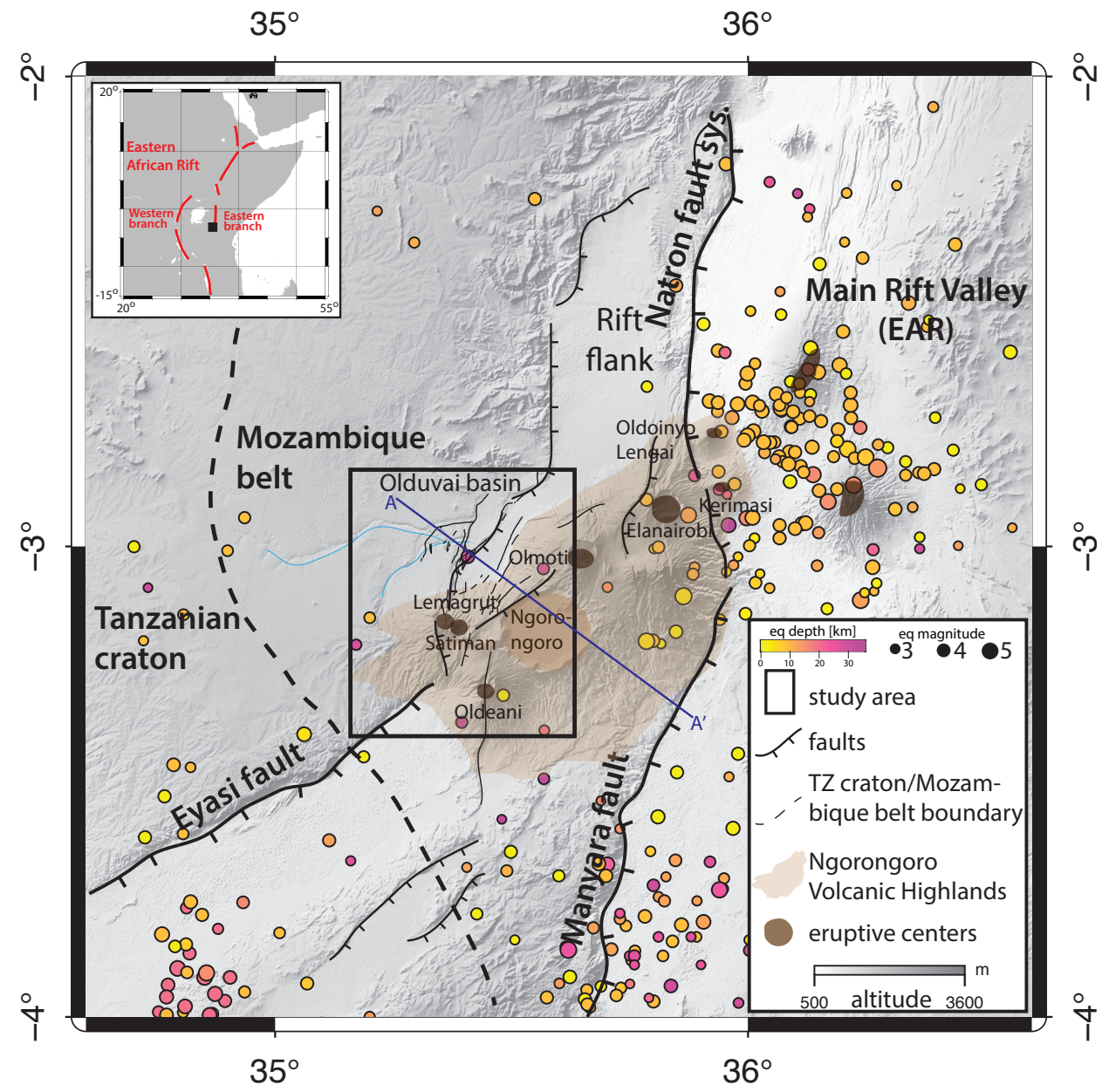

Figure 1: Tectonic sketch of the westernmost part of the North Tanzanian Divergence. Tectonic features are extracted from Ebinger et al. [1997], Ashley \& Hay [2002], Le Gall et al. [2008], Stollhofen \& Stanistreet [2012] and mapped by satellite images. The line AA' is the surface projection of the geological section shown in Figure 8. The study area in the black box is enlarged in Figure 2a. 

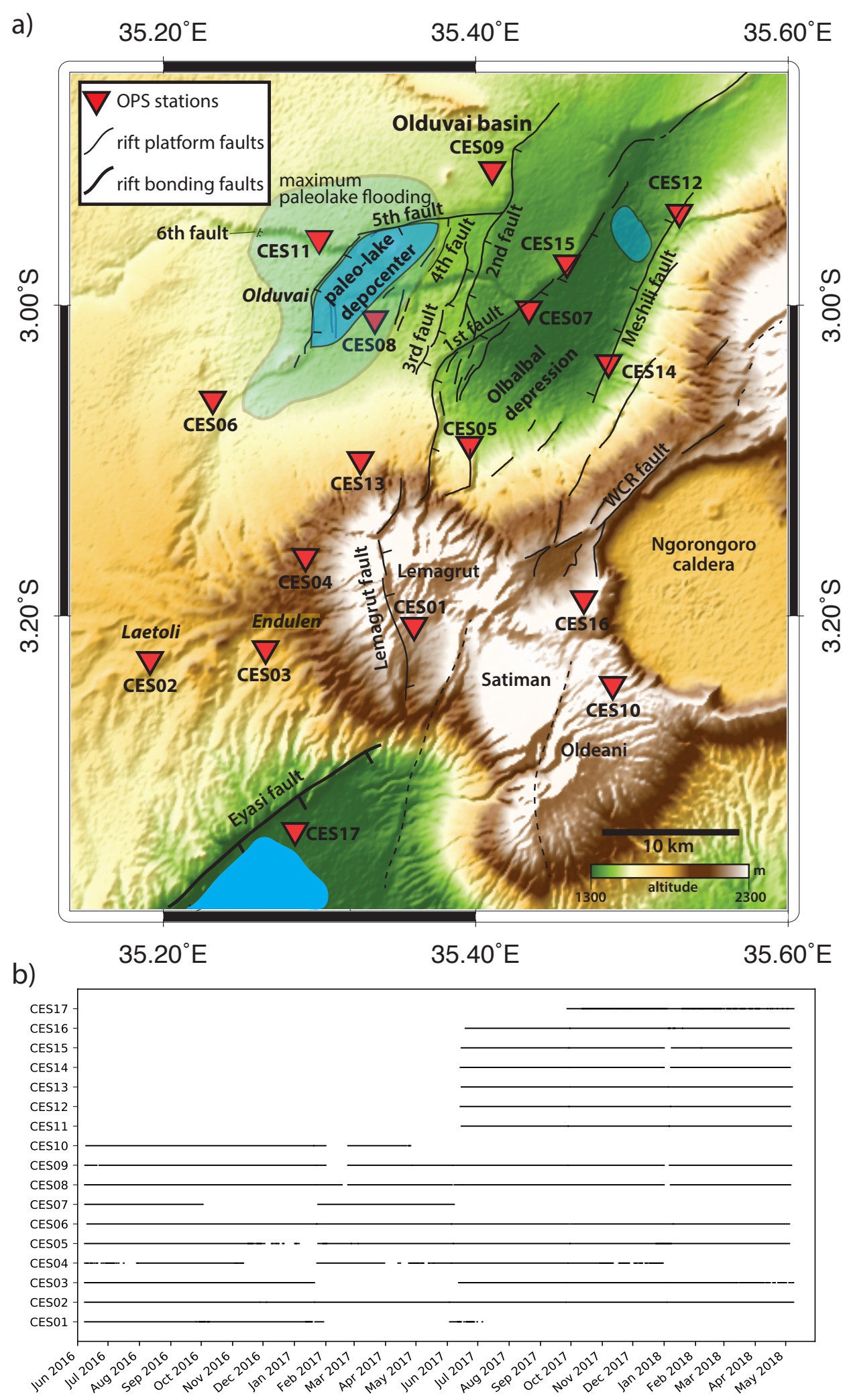

Figure 2: The OPS network and data availability. a) Map of the 17 seismic stations (red triangles) of the OPS network. Solid black lines are faults from Stollhofen \& Stanistreet [2012]. Dashed black lines are faults mapped by satellite images. Olduvai paleo-lake extension from Stanistreet et al. [2020b] b) Timeline (June 2016-May 2018) of data availability for each stations of the OPS network. 
a)
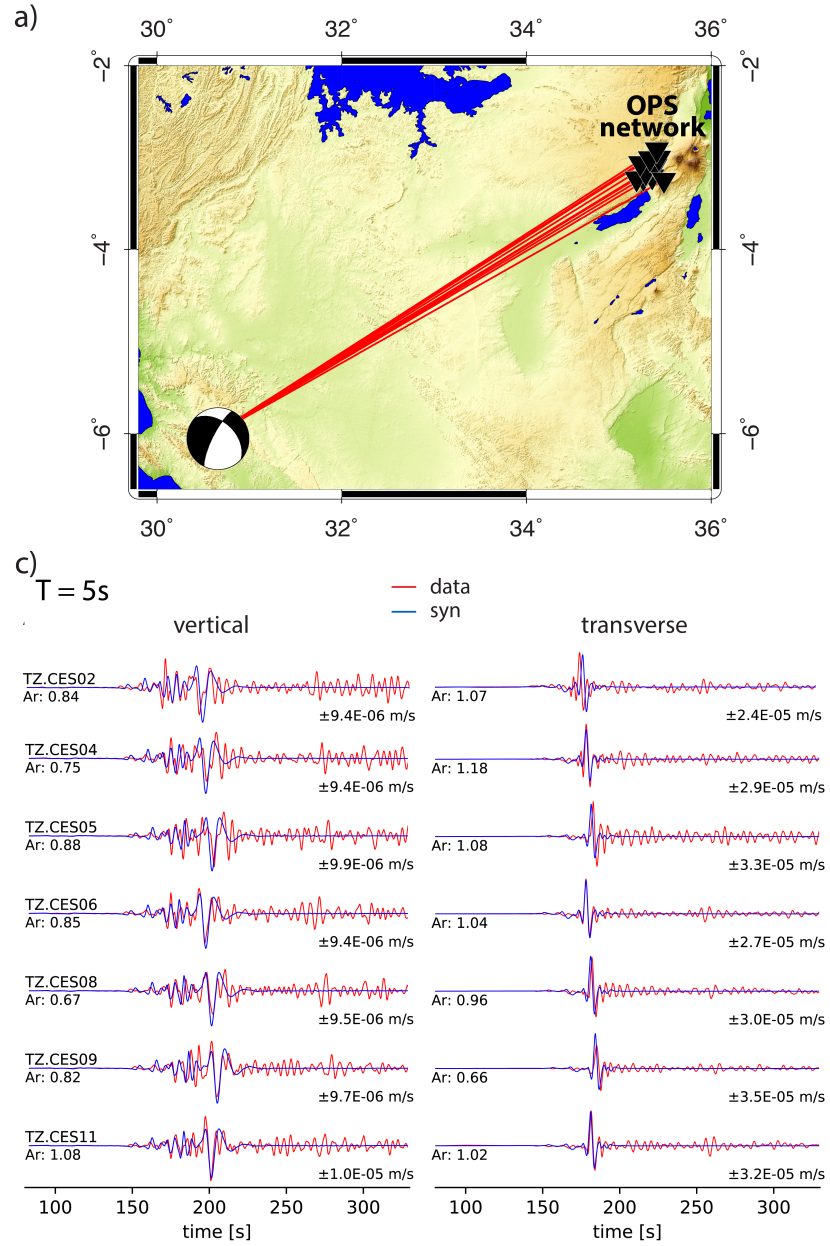

b)

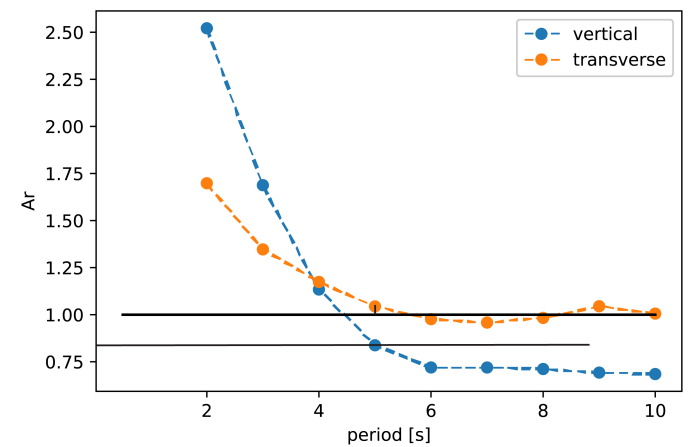

d)

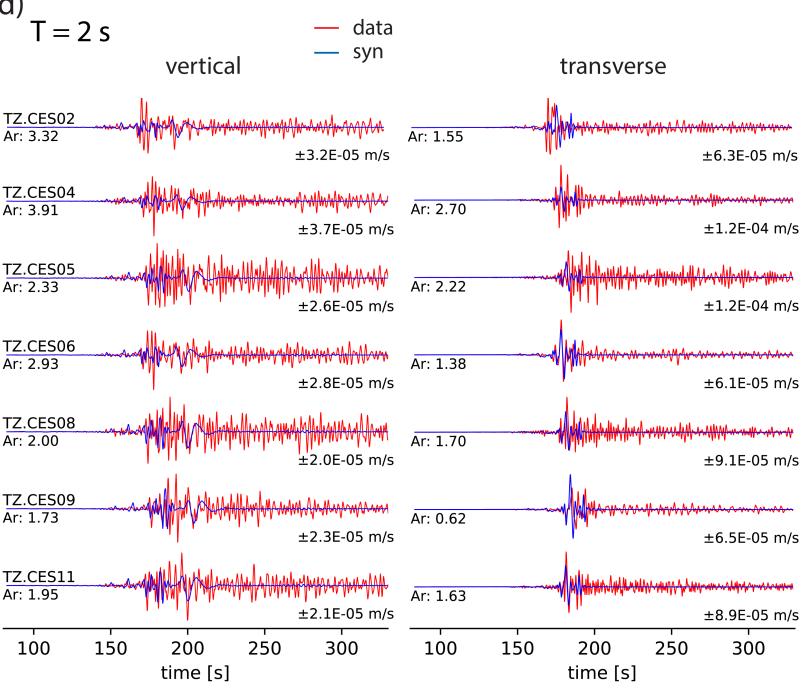

Figure 3: Validation of short-period data through simulation of the 22 October, 2017, Mw 5.1 earthquake. a) Source-receivers geometry. OPS indicates the average location of the OPS network. Red lines are the great-circle paths between the source and the receivers. b) Scatter of $A r=\max \left[A_{\text {data }}\right] / \max \left[A_{\text {syn }}\right]$ against the wave period. $A r$ valus are calculated as medians among all stations for each wave period c) Data-synthetic comparisons of the vertical and transverse waveforms for selected stations, low-pass filtered at $5 \mathrm{~s}$. ID of the station is indicated on the top left of the vertical component; $A r$ is indicated in the bottom left of each component and station; the maximum amplitude of the waveforms is indicated on the bottom right of each component and station. d) as c) but for waveforms that are low-pass filtered at $2 \mathrm{~s}$. 
a)

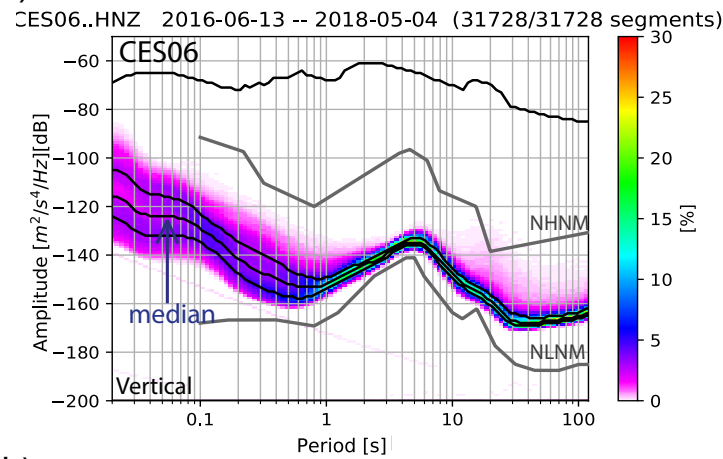

b)

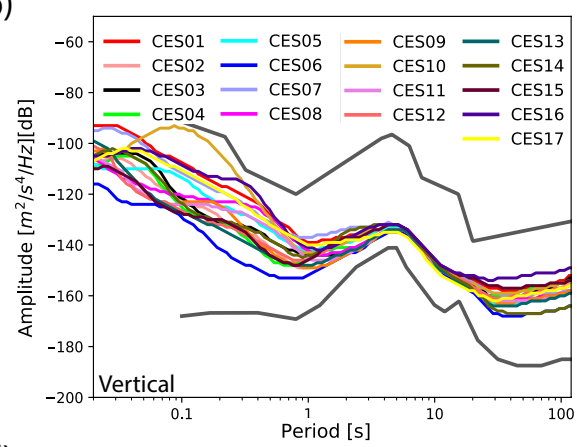

d)

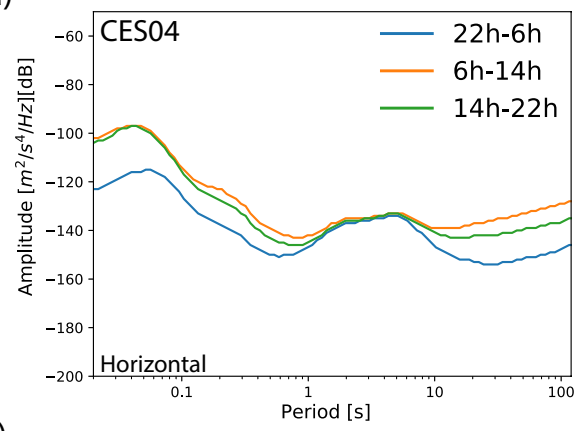

f)

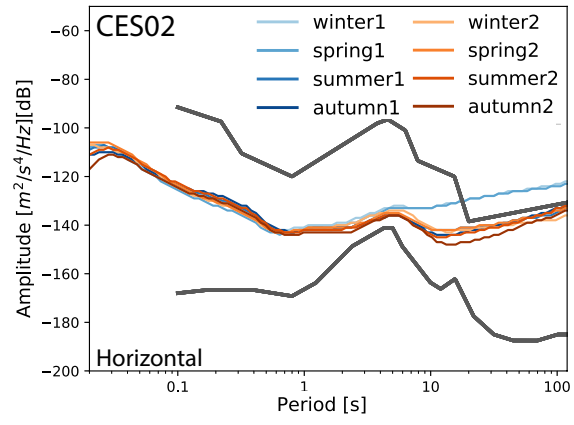

c)

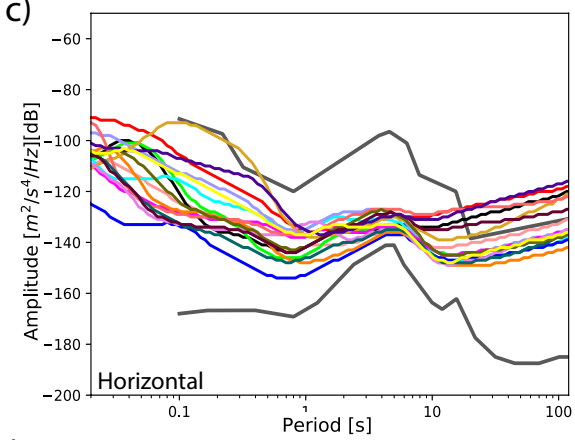

e)

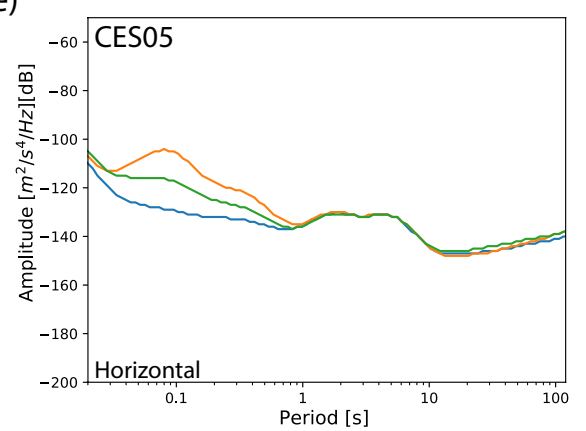

g)

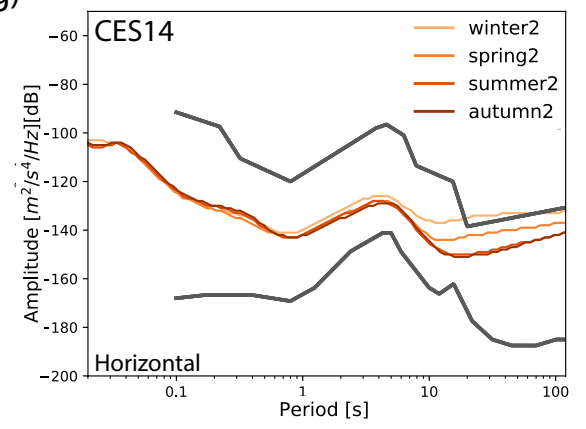

Figure 4: PPSD of the OPS network. a) Example of PPSD calculated for the vertical component of station CES06. b) Noise levels (medians of the PPSD) calculated for the vertical component of the OPS stations for the entire duration of the experiment. c) As in b) but for the horizontal component. d) Temporal variations of the noise level calculated for the horizontal component of the station CES02. Winter: June-August; Spring: Sep-Nov; Summer: DecemberFebruary; Autumn: March-May); Winter: March-April. 1 and 2 appended to the name of the season refer to the 1st and 2nd year of data acquisition. e) As in d) but for station CES14. f) Daily variations of noise level calculated for the horizontal component of station CES04 using all data available. g) As in f) but for the horizontal component. 


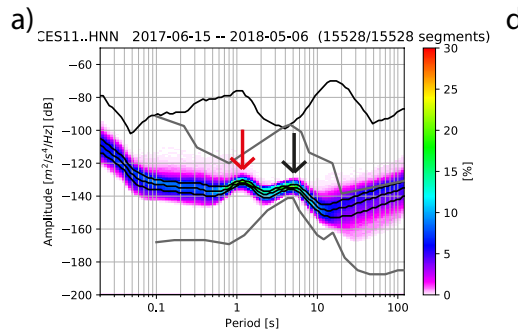

b)

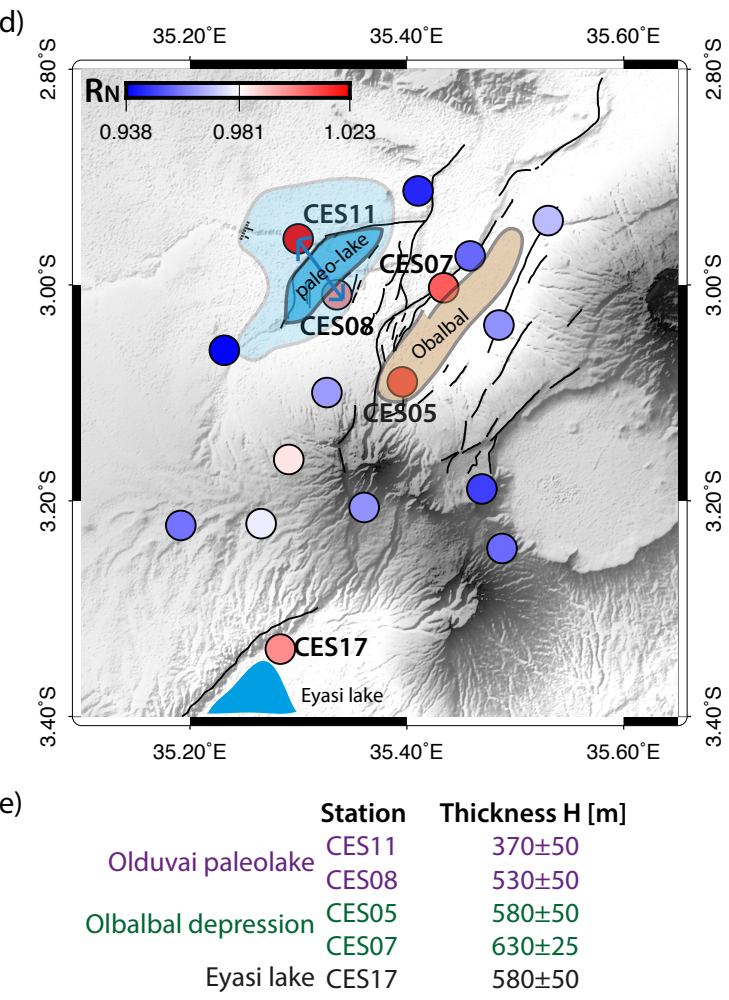

Figure 5: Estimates of the sedimentary covers in the NCA. a) PPSD for the horizontal component of the station CES11. Red arrow points at the wave-period for which the noise between $1-2 \mathrm{~s}$ is the largest $\left(T_{1-2 s}\right)$. Black arrow points at the wave-period for which the noise level between $3-10 \mathrm{~s}$ is the largest $\left(T_{3-10 s}\right)$. b) and c) as in a) but for station CES08 and CES05, respectively. d) Map of amplification $R_{N}$ calculated as the ratio between the amplitudes at $T_{3-10 s}$ (black arrows) and $T_{1-2 s}$ (red arrows). The arrow between CES11 and CES08 indicates the minimum extension of the Olduvai paleo-lake depocenter e) Estimates of the sedimentary covers below the stations estimated from the amplification at $T_{1-2 s}$. 

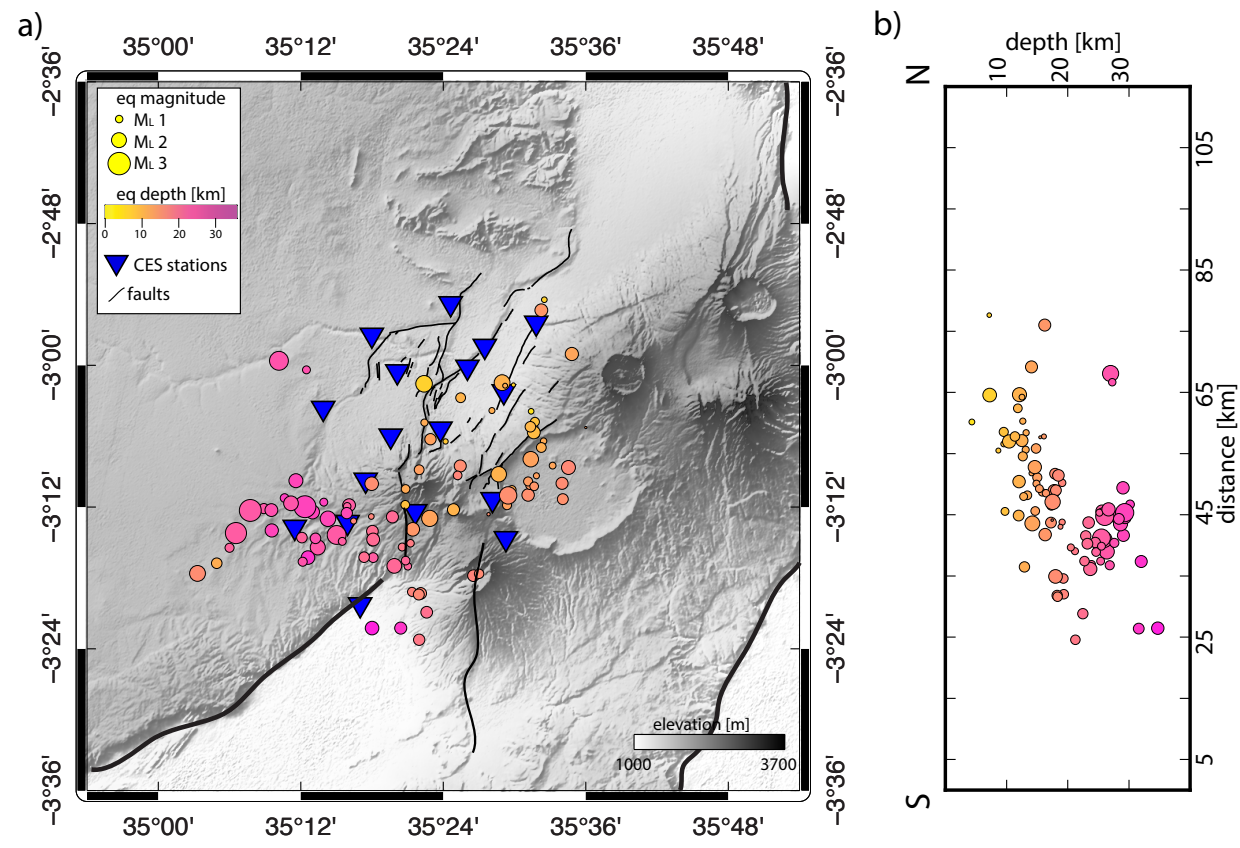

C)

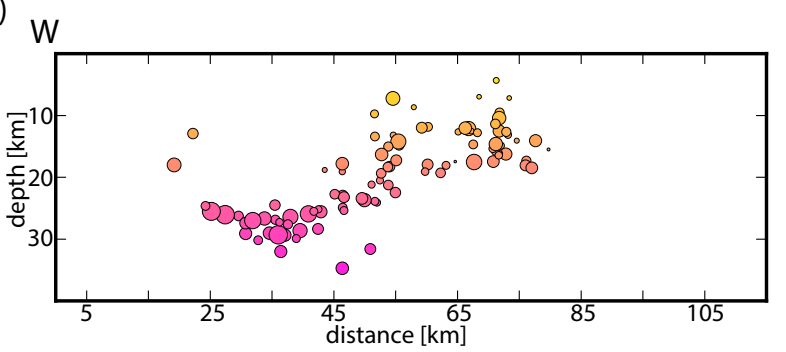

d)
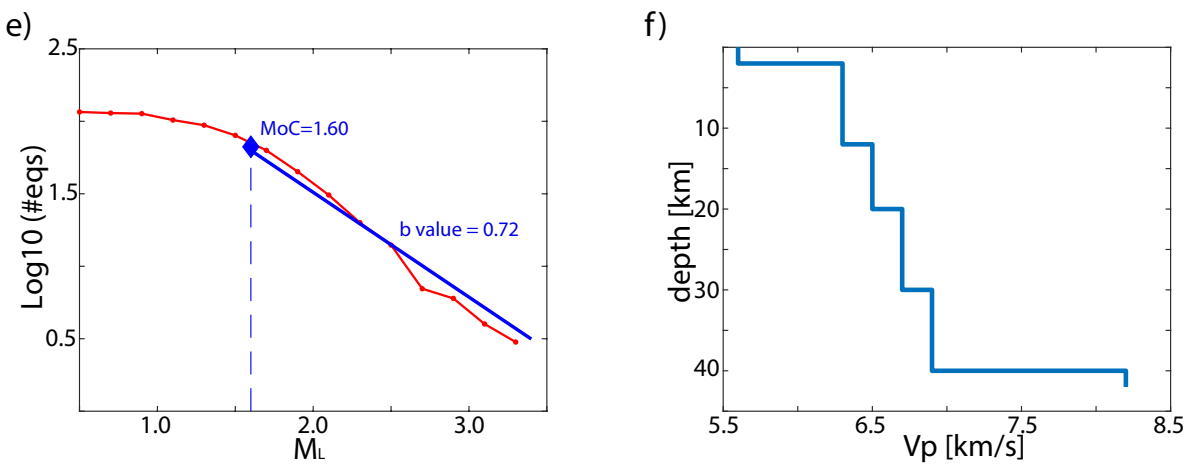

Figure 6: Seismicity in the NCA between June 2016-May 2018. a) Map view of seismicity recorded during the OPS experiment, color-coded by earthquake depth and symbol size scaled according to magnitude. See Figures 1 and 2 for faults labels b) North-south vertical section of seismicity. c) East-west vertical section of seismicity. d) Depth distribution of the shown seismicity. e) Magnitude-frequency distribution of the shown seismicity, with estimation of Mc and b-value. f) Starting model of P-wave velocity Vp used for earthquake location, modified from O'Donnell et al. [2013]. 
a)

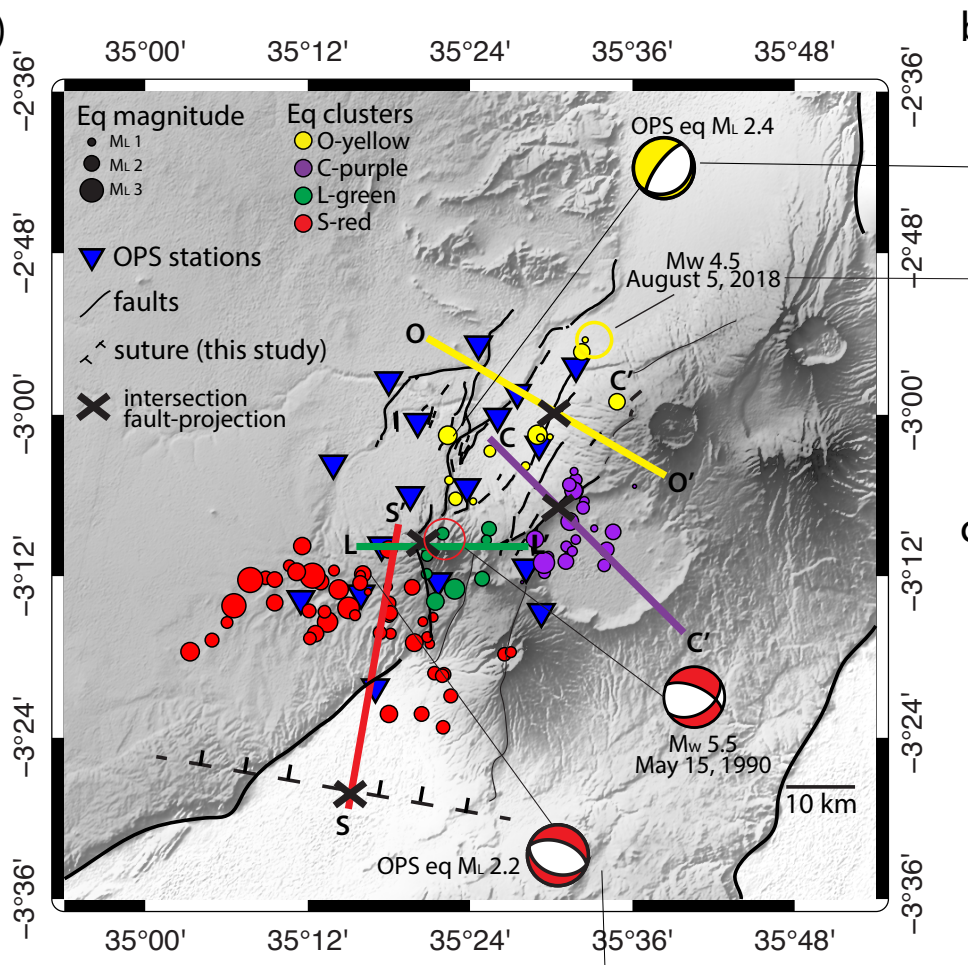

b)
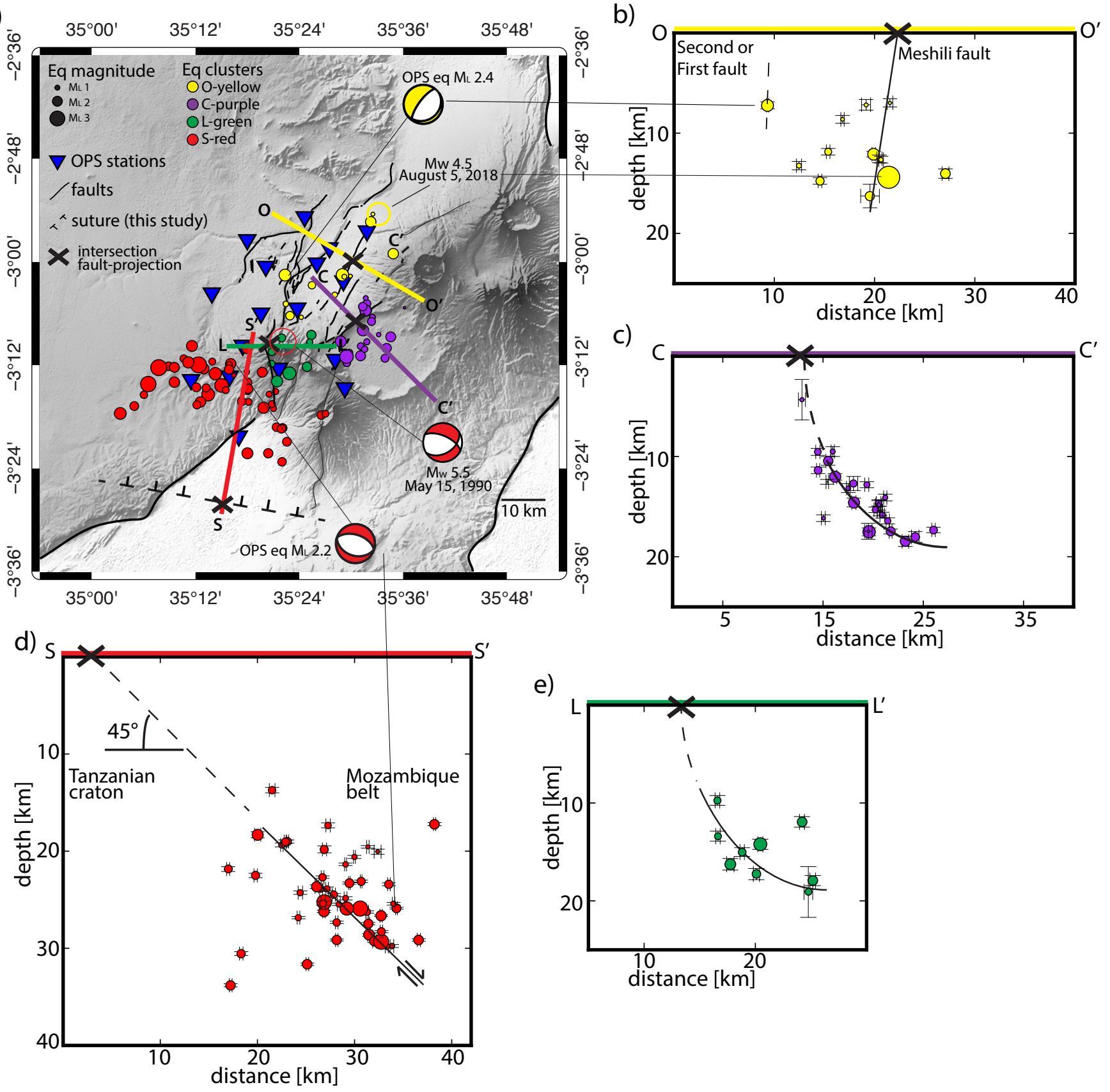

e)

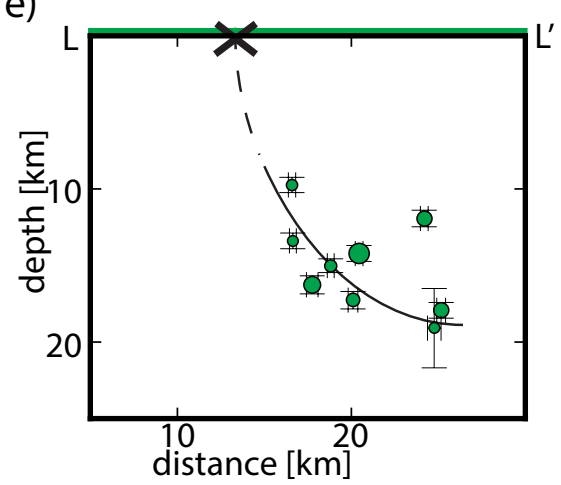

Figure 7: Analysis of earthquake clusters. a) Map showing the four different clusters that are recognized from the seismicity map in Figure 6. Colored lines show the surface projections of the four depth sections b), c), d) and e). Crosses correspond to intersections between faults and projections (also shown in the depth sections). Focal mechanisms from this study are referred as OPS eq $\mathrm{M}_{L} 2.4$ and the OPS eq $\mathrm{M}_{L} 2.2$. The focal mechanisms for the May 15, 1990, $\mathrm{Mw} 5.5$ earthquake is from the Global CMT catalogue (www.globalcmt.org). The location of the Mw 4.5 August 5, 2018, is an average from the locations in the IRIS (www.iris.edu) and USGS (www.earthquake.usgs.gov) catalogues. See Figures 1 and 2 for fault labels. b) Depth section of the O-yellow cluster showing the projected earthquakes on the planes that intersect the surface along the corresponding colored lines in the map. The cross corresponds to the intersection between faults and projections (also shown in a)). c) As in b) but for the C-purple cluster. d) As in b) but for the S-red cluster. e) As in b) but for the L-green cluster. 


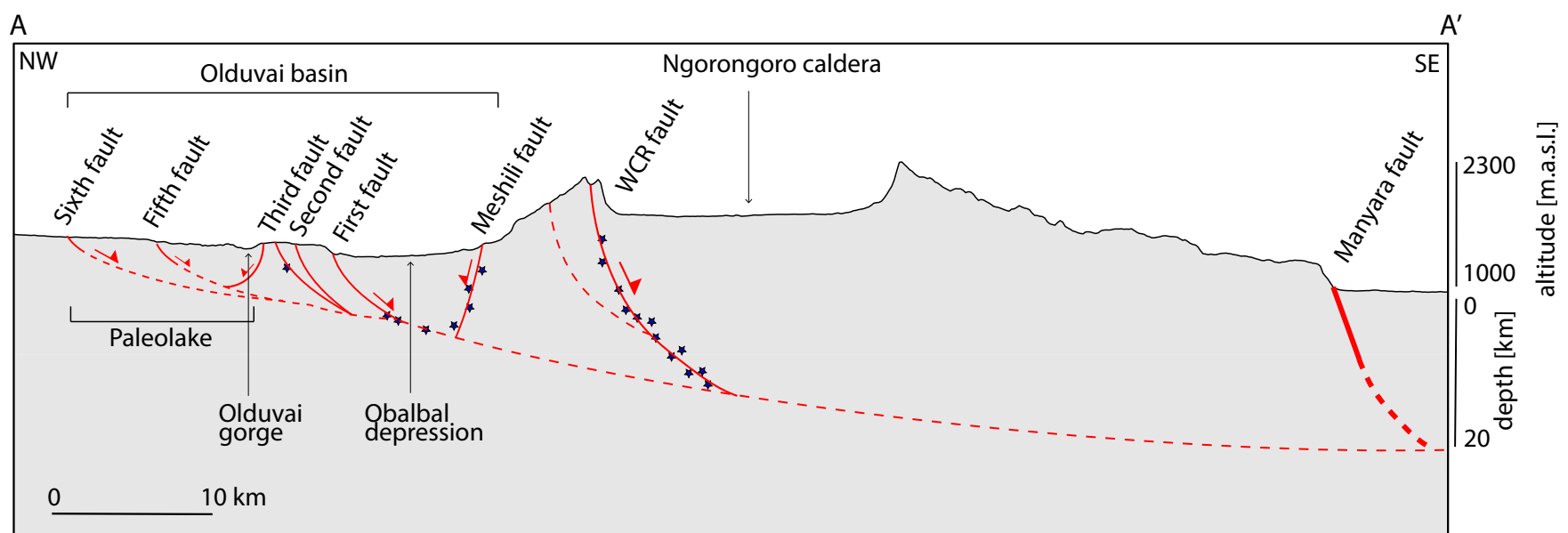

Figure 8: Cross-section of the extensional fault system that accommodates the Olduvai basin and defines the western margin of the eastern branch of the EAR. Solid lines represent faults either inferred in this study from the seismicity and sedimentary strata thickness estimates or extracted by Stollhofen \& Stanistreet [2012] and Stanistreet et al. [2020a]. Dashed lines are interpretative extrapolations. Blues stars schematically represent the seismic activity presented in this study. Location of the section is in Figure 1.

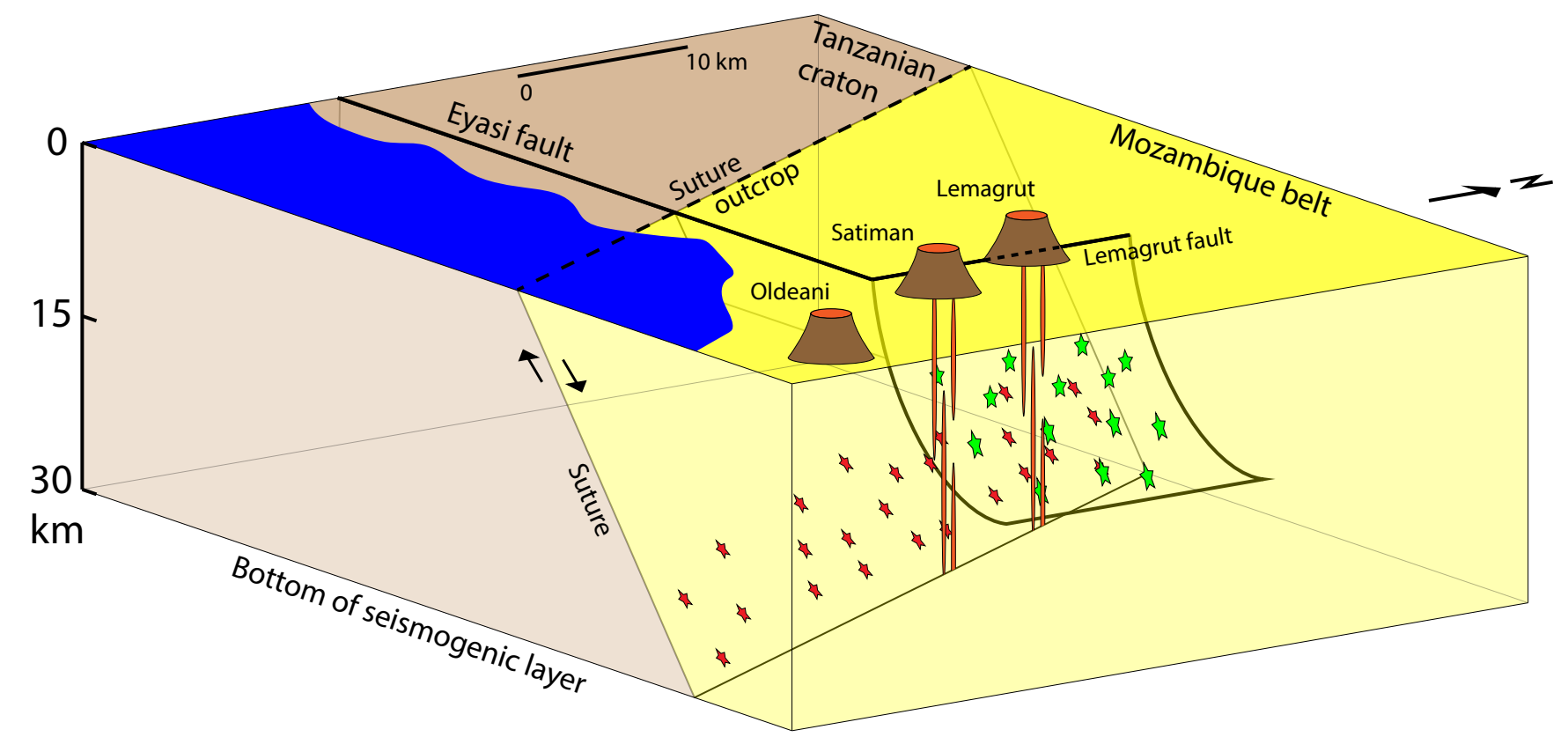

Figure 9: 3-D representation of the geometric relations between the Eyasi bounding fault, Lemagrut fault and the Tanzanian craton-Mozambique belt suture zone. Stars schematically represent the seismic activity recorded along the suture (in red) and the Lemagrut fault (in green). 